Author Accepted Manusceript

Accepted by Acta Materialia, 16 March 2019

\title{
Formation, Stability and Ultrahigh Strength of Novel Nanostructured Alloys by Partial Crystallization of High-Entropy (Fe0.25Co0.25Nio.25Cr0.125Mo0.125)86-89B11-14 Amorphous Phase
}

F. Wang ${ }^{1}$, A. Inoue ${ }^{1,2,3,4}$, F.L. Kong ${ }^{2}$, S.L. Zhu', E. Shalaan ${ }^{3}$, F. Al-Marzouki ${ }^{3}$, W.J. Botta ${ }^{5}$, C.S. Kiminami $^{5}$, Yu.P. Ivanov ${ }^{6}$ and A.L. Greer ${ }^{6}$

${ }^{1}$ School of Materials Science and Engineering, Tianjin University, Tianjin, 300072, China ${ }^{2}$ International Institute of Green Materials, Josai International University, Togane, 283-8555, Japan ${ }^{3}$ Department of Physics, King Abdulaziz University, Jeddah, 22254, Saudi Arabia ${ }^{4}$ MISiS, National University of Science and Technology, 119049, Moscow, Russia ${ }^{5}$ Department of Engineering and Materials, University Federal of Sao Carlos, Sao Carlos, 13565-905, Brazil

${ }^{6}$ Department of Materials Science and Metallurgy, University of Cambridge, Cambridge CB3 0FS, UK 


\begin{abstract}
Heating-induced

crystallization

of

high-entropy

(HE)

$\left(\mathrm{Fe}_{0.25} \mathrm{Co}_{0.25} \mathrm{Ni}_{0.25} \mathrm{Cr}_{0.125} \mathrm{Mo}_{0.125}\right)_{89-86} \mathrm{~B}_{11-14}$ amorphous (am) alloys is examined to develop new structural materials with low B contents. The crystallization of 11B alloy occurs in three stages: first nanoscale bcc precipitates form in the amorphous matrix, second nanoscale fcc precipitates form, and the residual amorphous phase disappears in the third stage which yields borides in addition to the bcc and fcc phases. Crystallization of 14B alloy is the same, except that the order of appearance of bcc and fcc is reversed. The bcc and fcc particle diameters are 5-15 $\mathrm{nm}$ and remain almost unchanged up to $\sim 960 \mathrm{~K}$. On annealing, ultrahigh hardness of 1500-1520 (unprecedented for boride-free structures) is attained just before the third crystallization stage. This hardening and the thermal stability of the novel $[\mathrm{am}+\mathrm{bcc}+\mathrm{fcc}]$ structures are remarkable at such low boron content, and encouraging for development as ultrahigh-strength alloys. The results are interpreted in terms of the nature and extent of partitioning of elemental components between the bcc/fcc phases and the amorphous matrix, and the size and defect structures of the bcc and fcc precipitates. The magnetic flux density at RT increases by precipitation of bcc and decreases by appearance of fcc. Slower quenching of the 11B alloy shows a pseudopolymorphic crystallization that may be characteristic of multicomponent HE systems.
\end{abstract}

Keywords; high-entropy alloy, nanophase structure, defect-free nanocrystal, ultrahigh strength, high thermal stability 


\section{Introduction}

Over the last three decades, much effort has been devoted to develop useful metallic materials by increasing the number of alloy components, as exemplified by the pioneering reports of bulk metallic glasses in 1989 [1], high-entropy (HE) bulk glassy alloys in 2002 [2], HE crystalline alloys in 2004 [3-5] and pseudo-high-entropy bulk metallic glasses in 2014 [6]. Although bulk metallic glasses have been widely used as structural, machinery and coating materials for $\mathrm{Zr}$ - and Fe-based alloy systems, and as soft-magnetic materials for ferromagnetic Fe-based alloy systems, there are few reports on engineering uses for other multicomponent alloys [7-10]. It is important to develop novel metallic materials with favorable engineering properties on the basis of advanced design of multicomponent compositions and structures.

Recently, we have studied the formation, thermal stability, mechanical properties and corrosion resistance of HE-type $\operatorname{LTM}(\mathrm{Fe}, \mathrm{Co}, \mathrm{Ni})-\mathrm{Cr}-\mathrm{B}$ and LTM-(Cr,Mo)-B amorphous and glassy alloys $[11,12]$ with the aim of finding new useful properties. Significant findings are: the formation of an amorphous phase incorporating uniformly dispersed nanoscale $\mathrm{Cr}_{5} \mathrm{~B}_{3}$ clusters for $\mathrm{Fe}-\mathrm{Co}-\mathrm{Ni}-\mathrm{Cr}-\mathrm{B} \mathrm{HE}$ alloys [11], and an amorphous phase field remarkably extended to $11-31$ at $\%$ B for Fe-Co-Ni-Cr-Mo-B HE alloys [12]. The partial replacement of $\mathrm{Cr}$ by Mo is very effective to extend the range of boron content for amorphous-phase formation, the marked extension to lower boron content being attributed to a HE effect [12]. Novel HE amorphous alloys with low metalloid content are attractive for future development of new structural and coating materials.

For systems such as LTM-(Cr,Mo)-based amorphous alloys with low metalloid contents of $11-14 \% \mathrm{~B}$, there have been no reports on thermal stability and crystallization in relation to mechanical, magnetic and chemical properties. Yet the low-metalloid HE 
amorphous alloys are expected to exhibit good mechanical properties, avoiding a catastrophic loss of plasticity in the as-cast or even the crystallized state. Here we study $\left(\mathrm{Fe}_{0.25} \mathrm{Co}_{0.25} \mathrm{Ni}_{0.25} \mathrm{Cr}_{0.125} \mathrm{Mo}_{0.125}\right)_{86-89} \mathrm{~B}_{11-14}(\mathrm{at} \%) \mathrm{HE}$ amorphous alloys. We find: (i) a novel sequence of crystallization reactions not previously been reported for annealing of any amorphous or bulk-glassy alloy; (ii) stability of microstructural scales as fine as $5 \mathrm{~nm}$ on annealing for $1.8 \mathrm{ks}$ at $900 \mathrm{~K}$; (iii) a sequence of structures, from partially to fully amorphous, as a function of cooling rate from the liquid. We relate the mechanical and magnetic properties to the structural and compositional changes, highlighting the novel microstructural features obtainable in these low-boron alloys.

\section{Experimental Methods}

High-order multicomponent alloys with nominal compositions (at \%) of $\left(\mathrm{Fe}_{0.25} \mathrm{Co}_{0.25} \mathrm{Ni}_{0.25} \mathrm{Cr}_{0.125} \mathrm{Mo}_{0.125}\right)_{86-89} \mathrm{~B}_{11-14}$ were chosen to explore $\mathrm{HE}$ effects on amorphous-phase forming ability and on crystallization [12]. Alloy ingots were prepared by arc-melting mixtures of pure $\mathrm{Fe}, \mathrm{Co} \mathrm{Ni}, \mathrm{Cr}$ and Mo metals, with purities above 99.8 wt $\%$, and crystal boron, purity $99.9 \mathrm{wt} \%$, under argon atmosphere. Ribbons with thickness of $20-50 \mu \mathrm{m}$ and width of $\sim 1.5 \mathrm{~mm}$ were melt-spun from the pre-alloyed ingots. The peripheral wheel speed was chosen in the range 15 to $40 \mathrm{~m} \mathrm{~s}^{-1}$ to control the ribbon thickness. The amorphicity of the ribbons was confirmed by X-ray diffraction and transmission electron microscopy (TEM). Thermal stability was examined by differential scanning calorimetry (DSC) at a heating rate of $0.67 \mathrm{~K} \mathrm{~s}^{-1}$. Hardness was measured with a Vickers hardness indenter under a load of 0.98 N. Plasticity was evaluated using a simple bend-test. Slip markings around Vickers hardness indents and on bent surfaces were observed in scanning electron microscopy (SEM). 
The distribution of alloy components was evaluated by energy dispersive X-ray (EDX) spectroscopy and X-ray micro-analysis, and the crystallized structure was also examined by X-ray diffraction and TEM. Annealing-induced nanoscale precipitates within the amorphous phase were characterized by TEM and aberration-corrected scanning TEM (Titan 80-300 with probe corrector).. Electron-energy loss spectroscopy (EELS) study was conducted using an FEI Tecnai Osiris TEM equipped with Quantum GIF (Gatan) and field-emission gun operated at $200 \mathrm{keV}$.

The magnetic properties of as-spun and annealed samples were measured with a vibrating sample magnetometer (VSM) under a magnetic field up to $850 \mathrm{kA} \mathrm{m}^{-1}$ and a B$\mathrm{H}$ loop tracer under a field up to $1000 \mathrm{~A} \mathrm{~m}^{-1}$ at room temperature.

\section{Results}

\subsection{Crystallization on heating 11 at\% B amorphous alloy}

Previous data obtained by X-ray diffraction and TEM show clearly that the as-spun 11 at\% B (11B) alloy ribbon consists of an amorphous phase without appreciable crystalline phase [12]. The DSC curves of the amorphous 11B-14B alloy ribbons (Fig. 1a) show trends in the onset temperatures of the first and the second exothermic reactions $\left(T_{\mathrm{x} 1}\right.$ and $\left.T_{\mathrm{x} 2}\right)$ (Fig. 1b). The DSC data in Fig. 1a suggest that these amorphous alloys crystallize through three or four stages. With increasing boron content up to $14 \%$, the area of the first peak remains nearly constant, while that of the second peak clearly decreases; and the onset temperature of the first peak increases slightly, while that of the second peak decreases.

Figure 2a shows X-ray diffraction patterns of 11B alloy ribbons annealed for $1.8 \mathrm{ks}$ at temperatures of $775 \mathrm{~K}, 900 \mathrm{~K}$ or $1120 \mathrm{~K}$ corresponding to each DSC peak. As identified 
in the figure, the newly precipitated phases are mainly (80-90\%) bcc for the first peak, fcc for the second peak and (LTM)Mo ${ }_{2} \mathrm{~B}$ and (LTM,Cr) $)_{2} \mathrm{~B}$ for the third peak. The crystallization sequence is thus: $[\mathrm{am}] \rightarrow$ [remaining amorphous $\left(\mathrm{am}^{\prime}\right)+$ bcc] $\rightarrow$ $\left[a m^{\prime \prime}+\mathrm{bcc}+\mathrm{fcc}\right] \rightarrow[\mathrm{bcc}+\mathrm{fcc}+$ borides $] . \quad$ It is notable that the coexistence of $[\mathrm{am} "+$ bcc $+\mathrm{fcc}]$ phases spans the extremely wide range from 830 to $960 \mathrm{~K}$.

Although the numbers of X-ray diffraction peaks for bcc and fcc phases are limited, their positions do allow evaluation of the lattice parameters: $0.288 \mathrm{~nm}$ for bec and $0.3626 \mathrm{~nm}$ for fcc. These values exceed those of $0.2876 \mathrm{~nm}$ for bcc FeCr phase [13] and $0.3591 \mathrm{~nm}$ for fcc $\mathrm{Fe}_{60} \mathrm{Ni}_{25} \mathrm{Cr}_{15}$ phase [14], presumably because of the supersaturation of Mo (larger atoms dissolved substitutionally) and B (smaller atoms dissolved interstitially). The bec and fcc phases include all the constituent elements of LTM, Cr, Mo and B (Sect. 3.3), and hence can be regarded as high-entropy nanophases with high dissolution strains. The extended solubility of molybdenum and boron in the bcc and fcc phases deviates from the equilibrium phase diagrams of the LTM-Mo and LTM-B systems, where $\mathrm{LTM}_{2} \mathrm{Mo},(\mathrm{Cr}, \mathrm{Mo})_{2} \mathrm{~B}, \mathrm{LTM}_{2} \mathrm{~B}$ and $\mathrm{LTM}_{3} \mathrm{~B}$ compounds appear at the composition of $11.1 \% \mathrm{Cr}, 11.1 \% \mathrm{Mo}$ and $11 \% \mathrm{~B}$ at room temperature [15].

Figures $2 \mathrm{~b}-\mathrm{d}$ show a bright-field TEM image, a selected-area electron diffraction pattern and a high-resolution TEM image of the 11B amorphous alloy annealed for $1.8 \mathrm{ks}$ at $775 \mathrm{~K}$, corresponding to the first DSC peak. In Fig. 2b, very fine precipitates with a diameter of $\sim 5 \mathrm{~nm}$ are uniformly dispersed in the residual amorphous matrix and the selected-area electron diffraction pattern (Fig. 2c) confirms that these are mainly bcc. Aberration-corrected high-angular annular dark field (HAADF) imaging confirmed the presence of uniformly dispersed nanocrystals, indicating that these are $\sim 90 \%$ bcc, $\sim 10 \%$ 
fcc.

The HRTEM image, Fig. 2d, confirms that the bcc and amorphous phases coexist and the precipitates appear spheroidal. From the electron diffraction pattern and the lattice imaging, the lattice parameter of the bcc phase is $0.2878 \mathrm{~nm}$, which is larger than that $(0.2842 \mathrm{~nm})$ for bcc $\mathrm{Fe}_{50} \mathrm{Co}_{50}$ alloy [16], and consistent with the result obtained from $\mathrm{X}$ ray diffraction (Fig. 2a). The lattice imaging shows no evidence for any defects.

Figures $3 \mathrm{a}-\mathrm{d}$ show a bright-field TEM image, a selected-area electron diffraction pattern, a dark-field TEM image taken from the fcc (111) reflection, and a high-resolution TEM image, of the 11B amorphous alloy annealed for $1.8 \mathrm{ks}$ at $900 \mathrm{~K}$, corresponding to the second DSC peak. The diffraction pattern shows the co-existence of bcc and fcc phases, as indexed in Fig. 3b, and indicated by the yellow and red colors. The dark-field image from the fcc (111) reflection reveals a uniform dispersion of fcc precipitates with diameter of 10-15 nm (Fig. 3c); as indicated by the arrows, the fcc phase includes a high density of planar faults. The HRTEM image (Fig. 3d) suggests that some bcc and fcc regions touch each other, without any intervening amorphous layer, though many bcc and fcc nanoparticles are isolated and surrounded by the remaining amorphous phase. No clear crystal orientation relationship at the interface between the bcc and fcc phases can be recognized, indicating that the phases have independent crystal orientations. There is no indication of particle coarsening through coalescence after the contact of the bcc and fcc phases. The precipitates are slightly larger for fcc than for bcc. The halo ring pattern in Fig. $3 b$ and the speckled contrast region in Fig. 3d reveal the residual existence of amorphous phase even at the second DSC peak temperature.

To clarify the nature of the faulted structure in Fig. 3c, HRTEM images of the fcc phase are shown in Fig. 3e,f. The high densities of planar faults and twin boundaries seen 
in these images were also confirmed by HRSTEM HAADF study. Thus, the nanoscale bcc and fcc phases have completely different internal structures: the absence of defects for the former and high densities of planar faults and twin boundaries for the latter. The high level of dissolved boron in these supersaturated solid solution (SSSS) fcc nanoparticles appears not to affect significantly the formation of planar faults.

The $\left[a m^{\prime \prime}+\mathrm{bcc}+\mathrm{fcc}\right]$ phase mixture, and the distinct two-stage crystallization mode, have not previously been reported for any amorphous or bulk-glassy alloy. The precipitates have diameters as small as $15 \mathrm{~nm}$ after annealing for $1.8 \mathrm{ks}$ at $900 \mathrm{~K}$. The novel decomposition, and the highly stable microstructure, reflecting sluggish growth or coarsening of the simple bcc and fcc structures, may originate from a high-entropy effect $[10]$.

\subsection{Crystallization on heating 14 at\% B amorphous alloy}

X-ray diffraction patterns (Fig. 4a) indicate a modified crystallization sequence for the 14B alloy: [am' + fcc] phases after annealing for $1.8 \mathrm{ks}$ at $783 \mathrm{~K}$ corresponding to the first DSC peak, [am" $+\mathrm{fcc}+\mathrm{bcc}]$ phases at $890 \mathrm{~K}$ corresponding to the second DSC peak, and $[\mathrm{fcc}+\mathrm{bcc}+$ borides $]$ at $1074 \mathrm{~K}$. To further characterize the primary precipitation, a bright-field TEM image, a selected-area electron diffraction pattern, a dark-field image taken from the (111) fcc reflection, and a high-resolution TEM image are shown in Figs 4b-e for the 14B alloy annealed for $1.8 \mathrm{ks}$ at $783 \mathrm{~K}$. Precipitates with diameters of 5-10 $\mathrm{nm}$ are uniformly dispersed and the diffraction pattern (Fig. 4c) shows that while most (80-90\%) of these are fcc, some are bcc, the two phases being indicated by the yellow and red colors respectively. The co-existence of the two crystallized phases is consistent with the overlap of the first and second DSC peaks (this overlap is 
greatest for 14B, Fig. 1a). The HRTEM image reveals that the precipitate diameter is $\sim 5 \mathrm{~nm}$ for bcc and $\sim 10 \mathrm{~nm}$ for fcc, suggesting faster growth for the latter, as already found for the 11B alloy. The precipitates appear roughly as spheres when bcc, and as prolate ellipsoids when fcc, the deviation from an equiaxed shape possibly associated with the internal faulting in the latter phase. The lattice parameters of the bcc and fcc phases, evaluated from Fig. 4c,e, are $0.2879 \mathrm{~nm}$ and $0.3627 \mathrm{~nm}$, respectively, also confirmed by HRSTEM. Just as for the 11B alloy, the primary and secondary precipitation phases show extremely fine particle diameters in the remaining amorphous phase; the microstructure thus seems largely independent of boron content in the $11-14$ at $\%$ B range.

\subsection{Redistribution of elemental constituents associated with crystallization}

The compositions of the phases in the $\left[\mathrm{am}^{\prime \prime}+\mathrm{bcc}+\mathrm{fcc}\right]$ mixture (in the 11B alloy annealed into the second DSC peak) were measured using EDX spectroscopy, which gives relative values for the metallic components, but not for boron (Suppl. Fig. 1a-c). EDX data obtained from regions A, B and C in Fig. 3a roughly correspond to fcc, bec and the residual amorphous phase respectively. The composition differences between the phases are likely to be greater than indicated, as activated volumes are such that the EDX spectra are likely to include some signal from the neighboring phases.

The relative differences in elemental contents between the bcc and residual amorphous phase range from 5 to $15 \%$. The bec phase is relatively rich in $\mathrm{Co}, \mathrm{Fe}$ and Mo, and poor in $\mathrm{Cr}$ and $\mathrm{Ni}$. The fcc phase is, to a very similar extent, relatively rich in $\mathrm{Co}$ and $\mathrm{Fe}$, and poor in $\mathrm{Cr}$, but shows much larger differences for the remaining metallic constituents. Relative to the residual amorphous phase, the fcc phase is $27 \%$ richer in $\mathrm{Ni}$ and $60 \%$ poorer in Mo. 
For the 14B alloy annealed into the second DSC peak, EDX data show similar partitioning of the metallic constituents as for the fcc phase in the previous case. The possible partitioning of boron was explored using electron-energy-loss spectroscopy (EELS). Figure 5 shows a HAADF STEM image and the corresponding EELS maps of the constituent-element distribution. These show that the nanocrystal regions high in Fe are low in $\mathrm{Cr}$ (as noted above) and also low in boron. This is shown most clearly in the combined map for Fe-Cr-B. The combination of EDX and EELS characterization shows that there is some partitioning of all constituent elements, even in the crystallization corresponding to the first DSC peak.

Overall, the crystallization of bcc and fcc phases appears to enrich the residual amorphous phase in $\mathrm{Cr}$, Mo and B. This co-partitioning may be correlated with the high stability of (Cr,Mo)-B bonds [12].

For the bcc primary phase in the crystallization of the 11B alloy, the changes in composition relative to the amorphous matrix are, however, modest, even nearpolymorphic. This is presumably because of the difficulty of element redistribution at the temperature of the first-stage crystallization, especially given the high driving force for bcc precipitation resulting from the low boron content.

Polymorphic crystallization of metallic glasses has been reported, for example, by precipitation of a compound from the amorphous phase with stoichiometric composition [17], by cold-rolling to induce precipitation of fcc-Al supersaturated solid solution (SSSS) from Al-based amorphous alloys [18], and by the low-temperature and long-time annealing of amorphous thin foils in in-situ TEM observation [19]. The present result indicates that the selection of a HE amorphous alloy composition with low metalloid content also provides an opportunity for near-polymorphic crystallization. 


\subsection{Crystallization-induced hardening}

Figure 6 shows the changes in Vickers hardness (Hv) associated with the crystallized structures of 11B-14B amorphous alloys resulting from $1.8 \mathrm{ks}$ anneals at selected annealing temperatures $\left(T_{\mathrm{a}}\right)$. The Hv values increase almost linearly with increasing $T_{\mathrm{a}}$, show maximum values of 1500-1550 and then decrease steeply with further increase of $T_{\mathrm{a}}$. There is no distinct change in the $T_{\mathrm{a}}$ dependence of $\mathrm{Hv}$ with $\mathrm{B}$ content. The $\mathrm{Hv}$ is 1050-1250 for the amorphous phase, 1250-1380 for [am' + bcc] phases, 1380-1550 for $[\mathrm{am} "+\mathrm{bcc}+\mathrm{fcc}]$ phases, and $1500-800$ for $[\mathrm{bcc}+\mathrm{fcc}+$ borides $]$. The linear increase of hardness in the former three structures without borides may arise largely from the changing composition of the residual amorphous phase as crystallization proceeds; this mechanism has been most clearly shown in Al-based amorphous alloys [Zho97,Han17]. It is notable that the alloys with co-existent $\left[\mathrm{am}^{\prime \prime}+\mathrm{bcc}+\mathrm{fcc}\right]$ phases (i.e. without any compound phases) exhibit very high hardnesses of $1500-1550 \mathrm{Hv}$, which have never before been obtained for LTM-based alloys with low boron contents of $11-14 \%$, even for a wide variety of composite mixtures of phases (amorphous, bcc, fcc, boride, carbide and intermetallic compounds [20-23]).

\subsection{Changes in magnetic properties}

Magnetic property changes can be used to analyze further the nature of the crystallization corresponding to the first and the second DSC peaks. Noting the significant difference in saturation magnetization $\left(M_{\mathrm{s}}\right)$ values at room temperature (RT) for bcc, fcc and amorphous phases, we measured the change in $M_{\mathrm{s}}$ with $T_{\mathrm{a}}$ for $1.8 \mathrm{ks}$ anneals for the $11 \mathrm{~B}$ alloy. The $M_{\mathrm{s}}$ increases rapidly in the $T_{\mathrm{a}}$ range corresponding to the first peak (Suppl. Fig. 2a,c), followed by a gradual decrease during the second peak, and 
then an increase again in the temperature range between the second and the third peaks. Considering that the crystallization sequence for the $11 \mathrm{~B}$ alloy is $[\mathrm{am}] \rightarrow\left[\mathrm{am}^{\prime}+\mathrm{bcc}\right]$ $\rightarrow\left[\mathrm{am}^{\prime \prime}+\mathrm{bcc}+\mathrm{fcc}\right] \rightarrow[\mathrm{bcc}+\mathrm{fcc}+$ borides $]$, the rapid initial increase of $M_{\mathrm{s}}$ can be attributed to the precipitation of the ferromagnetic bcc phase, while the decrease in $M_{\mathrm{s}}$ in the second stage follows from the precipitation of the fcc phase that is non-ferromagnetic at RT. The final increase in $M_{\mathrm{s}}$ with $[\mathrm{am} "+\mathrm{bcc}+\mathrm{fcc}]$ phases must be due to the combination of gradual changes of composition and volume fraction of the bec phase coexisting with the remaining amorphous phase. In addition, as shown by the $\mathrm{M}-\mathrm{H}$ hysteresis loops in Suppl. Figs 2a,b, the as-spun amorphous 11B alloy is paramagnetic and changes to ferromagnetic by the precipitation of the nanoscale bcc phase. The coercivity of the ferromagnetic $11 \mathrm{~B}$ alloy is highest $\left(846 \mathrm{~A} \mathrm{~m}^{-1}\right)$ for the $\left[\mathrm{am}^{\prime}+\mathrm{bcc}\right]$ phase mixture and decreases significantly to $237 \mathrm{~A} \mathrm{~m}^{-1}$ for the $\left[\mathrm{am}^{\prime \prime}+\mathrm{bcc}+\mathrm{fcc}\right]$ mixture, presumably because of crystallite growth and reduction of interface strains.

\subsection{Crystallization on cooling the liquid}

The potential engineering importance of the 11B alloy leads us to investigate further its amorphous phase formation ability. Figure 7 a shows the changes in structure, bending plasticity and $\mathrm{Hv}$ with peripheral wheel speed (which also affects ribbon thickness); the corresponding X-ray diffraction patterns are shown in Fig. 7b. On decreasing the wheel speed, the structure changes: $[\mathrm{am}] \rightarrow\left[\mathrm{am}^{\prime}+\mathrm{fcc}\right] \rightarrow\left[\mathrm{am}^{\prime \prime}+\mathrm{fcc}\right.$ + bcc] phases. The ductile-to-brittle transition corresponds well to the transition from $\left[\mathrm{am}^{\prime}+\mathrm{fcc}\right]$ to $\left[\mathrm{am}^{\prime \prime}+\mathrm{fcc}+\mathrm{bcc}\right]$ phases, indicating that the as-spun ribbon becomes brittle by the precipitation of bcc phase in conjunction with an increase in Hv. (A further 
decrease in boron content to $10 \mathrm{at} \%$ gives an $\left[\mathrm{am}^{\prime}+\mathrm{fcc}\right]$ phase mixture at a peripheral wheel speed of $40 \mathrm{~m} \mathrm{~s}^{-1}$.) These structural changes with wheel speed are different from the annealing-induced structural changes shown in Figs $2 \& 3$.

The fcc precipitates with diameter $\sim 100 \mathrm{~nm}$ (Fig. 7c,d) are large enough to obtain a diffraction pattern, and include a high density of internal defects. EDX spectra (Suppl. Fig. 3a,b) show the fcc phase to be rich in Fe and Ni, and poor in Mo, Co and Cr, but the relative differences in elemental contents (at.\%) between the fcc and residual amorphous phases are very minor, mostly $\sim 2 \%$. The largest difference is that the Mo content is $6 \%$ lower in the fcc phase. With such small differences, the crystallization can be regarded as pseudo-polymorphic, without the redistribution of elemental components expected in conventional solidification, and seen to some extent in crystallization of the amorphous phase (Sect. 3.3).

The mixed-phase alloy also exhibits good bending plasticity. As exemplified in Fig. 8 , shear bands are observed on the bent outer surface for the amorphous and $\left[\mathrm{am}^{\prime}+\right.$ fcc] phases for the 10B and 11B alloys. The deformation-induced shear-band density appears to be slightly higher for the $\left[\mathrm{am}^{\prime}+\mathrm{fcc}\right]$ phase mixture than for the amorphous single phase.

\section{Discussion}

\subsection{Correlations of structure, hardness and boron content for as-spun amorphous alloys}

Figure 9a,b shows the variation of Vickers hardness (Hv) with the Bragg angle of the amorphous halo in the X-ray diffraction pattern and with boron content for $\left(\mathrm{Fe}_{0.25} \mathrm{Co}_{0.25} \mathrm{Ni}_{0.25} \mathrm{Cr}_{0.125} \mathrm{Mo}_{0.125}\right)_{89-86} \mathrm{~B}_{11-14}$ amorphous alloys. With increasing boron 
content, the maximum of the amorphous halo shifts to lower angle, signifying an increase in the nearest-neighbor atomic distance in the amorphous structure, and the hardness decreases from 1120 to 1050 . Indeed, Hv, the halo position and boron content appear to be linearly related. It is surprising that $\mathrm{Hv}$ decreases with increasing boron content. This decrease is, however, attributable to the extension of the nearest-neighbor atomic distance, reflecting a weakening of the bonding between the constituent elements. On the other hand, on going from $11-14 \% \mathrm{~B}$ to the $15-31 \% \mathrm{~B}$ range, the composition dependence of $\mathrm{Hv}$ is inverted. With $15-31 \% \mathrm{~B}$, for $\left(\mathrm{Fe}_{0.25} \mathrm{Co}_{0.25} \mathrm{Ni}_{0.25} \mathrm{Cr}_{0.125} \mathrm{Mo}_{0.125}\right)_{69-85} \mathrm{~B}_{15-31}$ amorphous alloys, there is a clear tendency for $\mathrm{Hv}$ to increase with increasing boron content in conjunction with a decrease in the nearest-neighbor distance [12]. The continuous increase in $\mathrm{Hv}$, and decrease in nearest-neighbor atomic distance with $>15 \%$ $\mathrm{B}$ has been interpreted to originate from the increased number of preferential (Cr,Mo)-B atomic pairs [12]. The expansion of the nearest-neighbor distance with increasing boron content for 11-14 at\% B suggests that boron can dissolve interstitially, accompanied by a decrease in the number of $(\mathrm{Cr}, \mathrm{Mo})$ - $\mathrm{B}$ bonding pairs. The non-monotonic variation of $\mathrm{Hv}$ with boron content (Fig. 9b) is the first evidence for amorphous alloys that their mechanical strength can be significantly influenced by the dissolution state of the metalloid element.

\subsection{Difference between transformations on cooling of liquid and heating of amorphous} phase

Figure 10 shows a schematic temperature-time-transformation (TTT) diagram for the $\mathrm{HE}\left(\mathrm{Fe}_{0.25} \mathrm{Co}_{0.25} \mathrm{Ni}_{0.25} \mathrm{Cr}_{0.125} \mathrm{Mo}_{0.125}\right)_{89} \mathrm{~B}_{11}$ alloy subjected to cooling of the liquid or heating of the amorphous phase. When the liquid is cooled in processes such as melt- 
spinning, ejection-casting, or cooling on a copper hearth, the phase mixture in the solidified product changes in the order $[\mathrm{am}] \rightarrow\left[\mathrm{am}^{\prime}+\mathrm{fcc}\right] \rightarrow\left[\mathrm{am}^{\prime \prime}+\mathrm{fcc}+\mathrm{bcc}\right] \rightarrow$ $[\mathrm{fcc}+\mathrm{bcc}+$ borides $]$ with decreasing cooling rate. On the other hand, heating of the amorphous phase gives phase mixtures in the order $[\mathrm{am}] \rightarrow\left[\mathrm{am}^{\prime}+\mathrm{bcc}\right] \rightarrow\left[\mathrm{am}^{\prime \prime}+\right.$ $\mathrm{bcc}+\mathrm{fcc}] \rightarrow[\mathrm{bcc}+\mathrm{fcc}+$ borides $]$. It is notable that the sequence of phase mixtures is very similar on cooling more slowly and on heating, but with fcc being the primary precipitate phase in the former case, bcc in the latter. The fcc and bcc phases can each be regarded as a metastable SSSS containing large amounts of LTM, Cr, Mo and B. Ribbons consisting of an amorphous single phase, or mixed [am' $+\mathrm{fcc}]$ phases, when in the as-spun state exhibit good bending plasticity. However, any further decrease in cooling rate gives a mixed-phase $\left[\mathrm{am}^{\prime \prime}+\mathrm{fcc}+\mathrm{bcc}\right]$ ribbon that fractures during bending tests. Considering that as-spun $\mathrm{Fe}_{79} \mathrm{Cr}_{10} \mathrm{C}_{11}, \mathrm{Fe}_{79} \mathrm{Mo}_{10} \mathrm{C}_{11}$ and $\mathrm{Fe}_{79} \mathrm{~V}_{10} \mathrm{C}_{11}$ ribbons consisted of martensite ( $\left.\alpha^{\prime}\right)+$ fcc- $\gamma+M_{3} C$ [24], fcc- $\gamma+M_{3} C$ [25] and bcc- $\alpha+\mathrm{MC}$ [26] respectively, the multiplication of alloy components seems to be effective in enhancing the metastable phase-forming ability of the amorphous phase and supersaturated fcc and bcc phases. The enhancement is presumably due to the suppression of atomic mobility in the multi-component HE alloy. The formation of the metastable [am' $+\mathrm{fcc}],\left[\mathrm{am}^{\prime}\right.$ $+\mathrm{bcc}],[\mathrm{am} "+\mathrm{fcc}+\mathrm{bcc}]$, and [fcc $+\mathrm{bcc}+$ borides] phase mixtures by liquid cooling and amorphous heating for the HE LTM-(Cr,Mo)-B alloys is useful for development of highstrength metastable LTM-based alloys. 


\subsection{High thermal stability leading to three co-existing nanoscale phases}

We consider why an extremely fine mixed structure is formed and retained even after annealing for $1.8 \mathrm{ks}$ at temperatures up to $\sim 1120 \mathrm{~K}$. As shown in Figs 2 and 3, the particle size is $\sim 5 \mathrm{~nm}$ for the bcc phase and $10-15 \mathrm{~nm}$ for the fcc phase. The stability of the fine particle sizes at high temperature is presumed to originate from a combination of the following factors: (1) the low atomic mobility in multicomponent systems, inhibiting both decomposition of the bcc and fcc SSSS phases and solute partitioning between crystals and amorphous matrix, (2) suppression of cohesion and coalescence at the interface between the distinct bcc and fcc structures, (3) thermal stability of the surrounding residual amorphous phase, and (4) increased dissolution of boron in the coexisting amorphous, bcc and fcc phases which can be regarded as a high-entropy effect. The reduced enrichment of boron into the remaining amorphous phase reduces the driving force for precipitation of borides, stabilizing the nanoscale $\left[a m^{\prime \prime}+b c c+f c c\right]$ phase mixtures.

\subsection{Ultrahigh hardness}

Table 1 summarizes the preparation method and phase mixture obtained for Fe-, Coand Ni-based amorphous and nanocrystalline alloys with $<20 \%$ B showing hardness values mostly above 1200 reported to date [21-23,27-34]. Although hardness above 1200 has been obtained for [bcc + compound] and [ fcc + compound] mixed-phase alloys, there are no data on the formation of LTM-(Cr,Mo)-based alloys with $<20 \%$ B that have ultrahigh hardness above 1500. High hardness values exceeding 1200 for Fe- and Cobased crystalline alloys are attributed to the co-existence of rather large amounts of borides and/or carbides [00]. For amorphous alloys with much higher metalloid content, 
high hardness can be achieved without appreciable borides and carbides. For example, the hardness reaches 1397 for Fe-Co-Nb-B amorphous alloys [31] with metalloid content up to $30 \mathrm{at} \%$, and an ultrahigh hardness of 1500 is obtained for $(\mathrm{Fe}, \mathrm{Co}, \mathrm{Ni}, \mathrm{Cr}, \mathrm{Mo})_{69-70} \mathrm{~B}_{30}$ 31 amorphous alloys [ref.? - this was Fig. 16 in the original version of the text].

Figure $9 \mathrm{c}$ shows that the hardness increases with the total volume fraction of bcc and fcc phases for the 11B alloy consisting of [am], $\left[\mathrm{am}^{\prime}+\mathrm{bcc}\right]$, and $\left[\mathrm{am}^{\prime \prime}+\mathrm{bcc}+\mathrm{fcc}\right]$ phases. The total volume fraction $\left(V_{\mathrm{f}}\right)$ was estimated from the relation $V_{\mathrm{f}}=\left(\Delta H_{\mathrm{as}-\mathrm{q}}-\right.$ $\left.\Delta H_{\text {ann }}\right) / \Delta H_{\text {as-q }}$, where $\Delta H_{\text {as-q }}$ and $\Delta H_{\text {ann }}$ present the total exothermic heat up to the disappearance of amorphous phase for the as-spun and annealed samples respectively. The nanoscale $\left[\mathrm{am}^{\prime \prime}+\mathrm{bcc}+\mathrm{fcc}\right]$ phase mixture can show a hardness above 1500, achieving this level of ultrahigh hardness at much lower boron content (11 at $\%$ B) than would be effective in the monolithic amorphous phase. It is of particular interest to understand how this ultrahigh hardness can be reached at such low boron content.

The ultrahigh hardness values are presumed to originate from some combination of the following factors: (1) some partitioning of $\mathrm{Cr}$, Mo and $\mathrm{B}$ into residual amorphous phase, increasing its hardness, (2) the formation of SSSS precipitate phases with enhanced levels of alloy components and correspondingly high levels of dissolution strain resulting from the HE compositions, (3) the stability of the nanoscale phase mixtures, with particle diameters of $5 \mathrm{~nm}$ for bcc and 10-15 $\mathrm{nm}$ for fcc, and nanoscale inter-particle spacing of $\sim 5 \mathrm{~nm}$ occupied by the remaining amorphous phase, (4) the hardness of the precipitate phases that can be enhanced by the absence of dislocations in the bcc phase and by the high density of planar faults and twin boundaries in the fcc phase, (5) the absence of any close crystal orientation relationship between bcc and fcc phases resulting from their independent precipitation from the amorphous phase. For the bcc phase, the internal 
energy is presumably lowered by the annihilation of internal defects at the nanophase/amorphous interface. For the fcc phase, the high defect density may be due to its slightly larger particle diameter and the low stacking-fault energy arising from the high content of nickel and cobalt. The faults may be further stabilized by segregation of the dissolved species. The present work may be the first report of the co-existence of the perfect bcc and highly defected fcc nanoscale particles in the (Fe,Co,Ni)-based alloys.

The hardness decreases rapidly from 1500 to 800 by the precipitation of fine borides accompanied by significant growth of bcc and fcc particles and by the disappearance of the remaining amorphous phase. Strengthening associated with the co-existent perfect bcc and highly defected fcc nanoscale particles is evidently much more effective than any precipitation hardening caused by fine borides.

The present partially crystallized alloys have simultaneously the following features: (1) maintenance of the ultrahigh hardness after annealing for $1.8 \mathrm{ks}$ at the high temperature of $\sim 960 \mathrm{~K},(2)$ extremely low growth rates of bcc and fcc nanoscale particles in the residual amorphous phase over the wide range of 730 to $960 \mathrm{~K}$, (3) co-existent precipitation of perfect bcc and highly defected fcc nanoscale particles, and (4) the uniform dispersion of bcc and fcc particles each surrounded by the residual amorphous phase. This combination of features is particularly promising for development of heatresistant structural and coating materials.

\subsection{Relation between hardness and structure for as-spun partially crystallized alloys}

As shown in Fig. 7a, the hardness of the as-spun 11B alloy ribbons obtained by controlling the wheel rotation speed decreases by the precipitation of fcc phase while maintaining good bending plasticity, in contrast to the general tendency that the hardness 
increases by the precipitation of nanoscale crystalline phase for Al-, Fe- and Ni-based amorphous alloys [37]. In the as-spun structure of Fe-B [38], Fe-Co-B [35], Fe-Mo-B [36], Fe-Nb-B [37] and Ni-Cr-B [38] alloy ribbons with relatively lower boron contents of $15-16 \%$, the precipitation of bcc or fcc phases, accompanied by solute redistribution with the residual amorphous matrix, causes hardening and a plastic-to-brittle transition.

The importance of solute partitioning has been most clearly demonstrated in amorphous aluminum alloys. Precipitation of fcc Al-rich nanocrystals can be induced by annealing [Zho97] or by cold-rolling [18]. Partial crystallization induced by annealing is accompanied by hardening, attributed to solute enrichment of the amorphous matrix [Zho97]. In contrast, partial crystallization induced by cold-rolling appears to be polymorphic and is accompanied by softening [18].

In the present case, the softening (Fig. 7a) is also associated with a lack of solute partitioning in a pseudo-polymorphic transition (Sect. 3.6). The relative lack of solute partitioning during solidification on cooling, even at low boron content, is a unique crystallization mode that may be characteristic for HE systems in which solute transport is suppressed.

The decrease in hardness (Fig. 7a) is in direct contrast to the linear increase in hardness on annealing (Fig. 6). In addition to effects of differing solute redistribution, the nature of the precipitate phases may be relevant. The annealed alloys consist of perfect crystal bcc and highly defected fcc nanocrystals co-existing with the remaining amorphous phase, while the as-spun alloy ribbons prepared at lower wheel rotation speeds consist of an amorphous matrix and larger, $\sim 100 \mathrm{~nm}$ diameter, fcc particles containing a number of sub-grain boundaries. In the latter case, the absence of nanoscale bcc phase may be another reason for the lower hardness and for the good bending plasticity. 


\section{Conclusions}

The changes in microstructure and mechanical properties due to crystallization were examined for high-entropy (HE) $\left(\mathrm{Fe}_{0.25} \mathrm{Co}_{0.25} \mathrm{Ni}_{0.25} \mathrm{Cr}_{0.125} \mathrm{Mo}_{0.125}\right)_{86-89} \mathrm{~B}_{11-14}$ amorphous alloys.

(1) Crystallization of 11B alloy shows three stages: amorphous $(\mathrm{am}) \rightarrow\left[\mathrm{am}^{\prime}+\mathrm{bcc}\right]$ $\rightarrow\left[\mathrm{am}^{\prime \prime}+\mathrm{bcc}+\mathrm{fcc}\right] \rightarrow[\mathrm{bcc}+\mathrm{fcc}+$ borides $]$, with onsets at 775, 900 and $1120 \mathrm{~K}$. The preference for fcc over bcc increases with increasing boron content, and for 14B the crystallization stages change to: $[\mathrm{am}] \rightarrow\left[\mathrm{am}^{\prime}+\mathrm{fcc}\right] \rightarrow\left[\mathrm{am}^{\prime \prime}+\mathrm{fcc}+\mathrm{bcc}\right] \rightarrow[\mathrm{bcc}$ + fcc + borides], with onsets at 783,890 and $1074 \mathrm{~K}$.

(2) The first and second crystallization stages in both $11 \mathrm{~B}$ and $14 \mathrm{~B}$ alloys give precipitate diameters of $\sim 5 \mathrm{~nm}$ for bcc and $10-15 \mathrm{~nm}$ for fcc. These fine diameters remain almost unchanged over the wide temperature range up to $\sim 960 \mathrm{~K}$, associated with high stability of the residual amorphous phase. No appreciable internal defects are seen in the nanoscale bcc phase, while the nanoscale fcc phase includes high densities of planar faults and twin boundaries.

(3) There is some partitioning of metallic components between the bcc and residual amorphous phases, but the fractional changes in elemental contents are small, 5 to $15 \%$. The fcc nanocrystals show similar small changes, expect for Ni in which they are $27 \%$ richer, and Mo in which they are $60 \%$ poorer. Overall, crystallization enriches the residual amorphous phase in Cr, Mo and B, enhancing its stability. With the limited extent of partitioning, the bcc and fcc nanophases show non-equilibrium extensions of solubility.

(4) The Vickers hardness (Hv) of the as-spun amorphous alloys is $\sim 1120$ for $11 \mathrm{~B}$, and 
decreases with increasing boron content, to 1050 for $14 \mathrm{~B}$, associated with increasing nearest-neighbor atomic distance by the interstitial dissolution of boron. Almost independent of boron content, the $\mathrm{Hv}$ increases linearly with increasing annealing temperature $T_{\mathrm{a}}$, reaching $\sim 1520$ for nanoscale $[\mathrm{am} "+\mathrm{bcc}+\mathrm{fcc}]$ phase mixtures annealed for $1.8 \mathrm{ks}$ at $960 \mathrm{~K}$. This ultrahigh $\mathrm{Hv}$ can be attributed to: the composition of the residual amorphous phase, the fine diameters and contrasting defect structures of the bcc and fcc precipitates, supersaturation of alloy components in the precipitates and high levels of dissolution strain. The novel three-phase mixtures without borides achieve ultrahigh hardness at much lower B content than would be effective in other structures.

(5) The 11B amorphous alloy is paramagnetic at RT and changes to ferromagnetic with crystallization. The saturation magnetic flux density at RT increases rapidly with precipitation of the bcc phase, followed by a slight decrease on precipitation of the fcc phase, and then an increase as the alloy components gradually redistribute between the bcc, fcc and amorphous phases and the volume fraction of those phases also changes.

(6) Decreases in wheel rotation speed as well as a decrease in B content to $10 \%$ gives as-cast alloys with amorphous + fcc phases with lower Hv and good bending plasticity. The fcc phase has an average particle diameter of $\sim 100 \mathrm{~nm}$ and has nearly the same composition as the amorphous matrix. This suppression of solute partitioning may be characteristic of multicomponent HE systems.

(7) The discovery that ultrahigh Hv above 1500 can be attained for the $[\mathrm{am}$ " + bcc + fcc $]$ phase mixture without borides for the HE LTM-based alloys with low boron contents is promising for developing novel metastable high-strength structural and coating materials.

\section{Acknowledgements}


The authors are grateful for support from the Recruitment Program of Global Experts “1000 Talents Plan” (WQ20121200052), a Grant-in-Aid of MEXT (26630299) in Japan, the Deanship of Scientific Research (DSR), King Abdulaziz University, Jeddah, Saudi Arabia (1-1-435/HiCi) and the Ministry of Education and Science of the Russian Federation in the framework of the program aimed to increase the competitiveness of the National University of Science and Technology, "MISiS" (No. K2-2017-002). ALG and YPI acknowledge support from the European Research Council under the European Union's Horizon 2020 research and innovation programme (grant ERC-2015AdG-695487: ExtendGlass).

\section{References}

[1] A. Inoue, K. Kita, T. Zhang, T. Masumoto, An amorphous $\mathrm{La}_{55} \mathrm{Al}_{25} \mathrm{Ni}_{20}$ alloy prepared by water quenching, Mater. Trans. JIM, 30 (1989) 722-725.

[2] L. Ma, L. Wang, T. Zhang, A. Inoue, Bulk glass formation of Ti-Zr-Hf-Cu-M (M= Fe, Co, Ni) alloys, Mater. Trans. 43 (2002) 277-280.

[3] K.B. Kim, P.J. Warren, B. Cantor, Metallic glass formation in multicomponent (Ti, Zr, Hf, Nb)-(Ni, Cu, Ag)-Al alloys, J. Non-Cryst. Solids 317 (2003) 17-22.

[4] B. Cantor, I.T.H. Chang, P. Knight, A.J.B. Vincent, Microstructural development in equiatomic multicomponent alloys, Mater. Sci. Eng. A 375-377 (2004) 213-218.

[5] J.W. Yeh, S.K. Chen, S.J. Lin, J.Y. Gan, T.S. Chin, T.T. Shun, C.H. Tsau, S.Y. Chang, Nanostructured high-entropy alloys with multiple principal elements: Novel alloy design concepts and outcomes, Adv. Eng. Mater. 6 (2004) 299-303.

[6] A. Inoue, Z. Wang, D.V. Louzguine-Luzgin, Y. Han, F.L. Kong, E. Shalaan, F. AlMarzouki, Effect of high-order multicomponent on formation and properties of $\mathrm{Zr}^{-}$ based bulk glassy alloys, J. Alloy Comp. 638 (2015) 197-203.

[7] A. Inoue, A. Takeuchi, Recent development and application products of bulk glassy alloys, Acta Mater. 59 (2011) 2243-2267.

[8] C. Suryanarayana, A. Inoue, Bulk Metallic Glasses, Second Edition, CRC Press 2017.

[9] M.F. Ashby, A.L. Greer, Metallic glasses as structural materials, Scripta Mater. 54 (2006) 321-326. 
[10] B.S. Murty, J.W. Yeh, S. Ranganathan, High-Entropy Alloys, Butterworth-Heinemann, 2014 .

[11] J. Ding, A. Inoue, Y. Han, F.L. Kong, S.L. Zhu, Z. Wang, E. Shalaan, F. Al-Marzouki, High entropy effect on structure and properties of ( $\mathrm{Fe}, \mathrm{Co}, \mathrm{Ni}, \mathrm{Cr}$ )-B amorphous alloys, J. Alloy Compd. 696 (2017) 345-352.

[12] F. Wang, A. Inoue, F.L. Kong, Y. Han, S.L. Zhu, E. Shalaan, F. Al-Marzouki, Formation, thermal stability and mechanical properties of high entropy ( $\mathrm{Fe}, \mathrm{Co}, \mathrm{Ni}, \mathrm{Cr}, \mathrm{Mo})-\mathrm{B}$ amorphous alloys, J. Alloy Comp. 732 (2018) 637-645.

[13] G. Hausch, E. Török, Thermal expansivity and elastic constants of CrFe alloys, Phys. Stat. Sol. (a) 40 (1977) 55-62.

[14] S. Ōhara, S. Kōmura, T. Takeda, Magnetic properties of pseudo-iron $\mathrm{Fe}_{1-x}\left(\mathrm{Cr}_{0.5} \mathrm{Ni}_{0.5}\right)_{x}$ ternary alloys, J. Phys. Soc. Jpn 34 (1973) 1472-1476.

[15] H. Okamoto, Phase Diagrams for Binary Alloys, 2 ed., ASM International, Materials Park, Ohio, 2010.

[16] G. Pourroy, S. Läkamp, S. Vilminot, Stabilization of iron-cobalt alloy isomorphous of $\alpha$ -Mn in a metal ferrite composite, J. Alloy Comp. 244 (1996) 90-93.

[17] A.L. Greer, Metallic Glasses, Chap. 4 in D.E. Laughlin, K. Hono (eds), Physical Metallurgy (Fifth Edition), Vol. 1, Elsevier, Oxford, 2014, pp. 305-385.

[18] H.W. Bi, A. Inoue, F.F. Han, Y. Han, F.L. Kong, S.L. Zhu, E. Shalaan, F. Al-Marzouki, A.L. Greer, Novel deformation-induced polymorphic crystallization and softening of $\mathrm{Al}^{-}$ based amorphous alloys, Acta Mater. 147 (2018) 90-99.

[19] T. Masumoto, H. Kimura, A. Inoue, Y. Waseda, Structural stability of amorphous metals, Mater. Sci. Eng. 23 (1976) 141-144.

[20] A. Inoue, B.L. Shen, A.R. Yavari, A.L. Greer, Mechanical properties of Fe-based bulk glassy alloys in Fe-B-Si-Nb and Fe-Ga-P-C-B-Si systems, J. Mater. Res. 18 (2003) 1487-1492.

[21] V. Ponnambalam, S.J. Poon, G.J. Shiflet, Fe-based bulk metallic glasses with diameter thickness larger than one centimeter, J. Mater. Res. 19 (2004) 1320-1323.

[22] X. Wu, Y. Hong, Fe-based thick amorphous-alloy coating by laser cladding, Surf. Coat. Technol. 141 (2001) 141-144.

[23] A.S. Nouri, Y. Liu, J. Lewandowski, Effects of thermal exposure and test temperature on structure evolution and hardness/viscosity of an iron-based metallic glass, Metal. Mater. Trans. A 40 (2009) 1314-1323.

[24] T. Minemura, A. Inoue, T. Masumoto, Metastable austenite phase in rapidly quenched Fe-Cr-C alloys, Trans. Iron Steel Inst. Jpn 21 (1981) 649-655.

[25] T. Minemura, A. Inoue, Y. Kojime, T. Masumoto, Microstructure and mechanical 
properties of nonequilibrium austenite in $\mathrm{Fe}-\mathrm{C}-(\mathrm{Mo}, \mathrm{W})$ systems rapidly quenched from melts, Trans. Iron Steel Inst. Jpn 22 (1982) 934-941.

[26] A. Inoue, Y. Harakawa, M. Oguchi, T. Masumoto, Metastable MC phase in meltquenched $\mathrm{Fe}-\mathrm{C}-\mathrm{V}$ and $\mathrm{Fe}-\mathrm{C}-\mathrm{V}-(\mathrm{Cr}$ or $\mathrm{Mo})$ alloys-mechanical properties and powderforming tendency by comminution, J. Mater. Sci. 21 (1986) 1310-1320.

[27] A. Inoue, B.L. Shen, C.T. Chang, Super-high strength of over $4000 \mathrm{MPa}$ for Fe-based bulk glassy alloys in $\left[\left(\mathrm{Fe}_{1-x} \mathrm{Co}_{x}\right)_{0.75} \mathrm{~B}_{0.2} \mathrm{Si}_{0.05}{ }_{96} \mathrm{Nb}_{4}\right.$ system, Acta Mater. 52 (2004) 4093-4099.

[28] Z.P. Lu, C.T. Liu, W.D. Porter, Role of yttrium in glass formation of Fe-based bulk metallic glasses, Appl. Phys. Lett. 83 (2003) 2581-2583.

[29] A. Inoue, T. Zhang, A. Takeuchi, Bulk amorphous alloys with high mechanical strength and good soft magnetic properties in Fe-TM-B (TM=IV-VIII group transition metal) system, Appl. Phys. Lett. 71 (1997) 464-466.

[30] Z. Lu, C. Liu, C. Carmichael, W. Porter, S. Deevi, Bulk glass formation in an Fe-based Fe-Y-Zr-M (M= Cr, Co, Al)-Mo-B system, J. Mater. Res. 19 (2004) 921-929.

[31] Z.Y. Chang, X.M. Huang, L.Y. Chen, M.Y. Ge, Q.K. Jiang, X.P. Nie, J.Z. Jiang, Catching Fe-based bulk metallic glass with combination of high glass forming ability, ultrahigh strength and good plasticity in Fe-Co-Nb-B system, Mater. Sci. Eng. A 517 (2009) $246-248$.

[32] H. Choi-Yim, D. Xu, W.L. Johnson, Ni-based bulk metallic glass formation in the Ni$\mathrm{Nb}-\mathrm{Sn}$ and Ni-Nb-Sn-X (X=B,Fe,Cu) alloy systems, Appl. Phys. Lett. 82 (2003) 10301032 .

[33] V. Keryvin, V.H. Hoang, J. Shen, Hardness, toughness, brittleness and cracking systems in an iron-based bulk metallic glass by indentation, Intermet. 17 (2009) 211217.

[34] J.T. Kim, S.H. Hong, C.H. Lee, J.M. Park, T.W. Kim, W.H. Lee, H.I. Yim, K.B. Kim, Plastic deformation behavior of $\mathrm{Fe}-\mathrm{Co}-\mathrm{B}-\mathrm{Si}-\mathrm{Nb}-\mathrm{Cr}$ bulk metallic glasses under nanoindentation, J. Alloy Comp. 587 (2014) 415-419.

[35] A. Inoue, B.L. Shen, C.T. Chang, Fe- and Co-based bulk glassy alloys with ultrahigh strength of over $4000 \mathrm{MPa}$, Intermet. 14 (2006) 936-944.

[36] A. Inoue, T. Masumoto, S. Arakawa, T. Iwadachi, Amorphous high-carbon alloy steels rapidly quenched from melts, Trans. Jpn Inst. Metals 19 (1978) 303-304.

[37] A. Inoue, H. Tomioka, T. Masumoto, Mechanical properties of ductile Fe-Ni-Zr and Fe$\mathrm{Ni}-\mathrm{Zr}(\mathrm{Nb}$ or $\mathrm{Ta})$ amorphous alloys containing fine crystalline particles, J. Mater. Sci. 18 (1983) 153-160.

[38] T. Kemény, I. Vincze, B. Fogarassy, S. Arajs, Structure and crystallization of Fe-B 
metallic glasses, Phys. Rev. B, 20 (1979) 476-488.

Additional references in the text

[Zho97] Z.C. Zhong, X.Y. Jiang, A.L. Greer, Nanocrystallization in Al-based amorphous alloys, Philos. Mag. B 76 (1997) 505-510.

[Han17] F.F. Han, A. Inoue, Y. Han, F.L. Kong, S.L. Zhu, E. Shalaan, F. Al-Marzouki, A.L. Greer, Novel heating-induced reversion during crystallization of Al-based glassy alloys, Sci. Reports 7 (2017) 46113. 
Table 1. Microstructure, hardness, preparation condition and alloy compositions for the HE 11B and 14B alloys in as-spun amorphous and partially and fully crystallized states, together with published data for Fe-, Co- and Ni-based amorphous and crystallized alloys containing metalloid contents below 20 at $\%$

The data for the HE 11B and 14B alloys do not seem to be shown in the table, although they are mentioned in the text above. 


\begin{tabular}{|c|c|c|c|c|}
\hline & Preparation method & Structure & Vickers hardness & Reference \\
\hline $\mathrm{Fe}_{48} \mathrm{Cr}_{15} \mathrm{Mo}_{14} \mathrm{Er}_{2} \mathrm{C}_{15} \mathrm{~B}_{6}$ & copper mold casting & amorphous & $1200-1300$ & [21] \\
\hline $\mathrm{Fe}_{57} \mathrm{Co}_{8} \mathrm{Ni}_{8} \mathrm{Zr}_{10} \mathrm{Si}_{4} \mathrm{~B}_{13}$ & laser cladding & amorphous & 1270 & [22] \\
\hline $\mathrm{Fe}_{48} \mathrm{Cr}_{15} \mathrm{Mo}_{14} \mathrm{Y}_{2} \mathrm{C}_{15} \mathrm{~B}_{6}$ & drop-cast & amorphous & $\sim 1200$ & [23] \\
\hline $\mathrm{Fe}_{79} \mathrm{Cr}_{10} \mathrm{C}_{11}$ & melt-spinning & $\alpha^{\prime}+\gamma+\mathrm{M}_{3} \mathrm{C}$ & 630 & [24] \\
\hline $\mathrm{Fe}_{79} \mathrm{Mo}_{10} \mathrm{C}_{11}$ & melt-spinning & $\gamma+\mathrm{M}_{3} \mathrm{C}$ & 700 & [25] \\
\hline $\mathrm{Fe}_{47} \mathrm{~V}_{20} \mathrm{Cr}_{15} \mathrm{C}_{18}$ & melt-spinning & $\alpha+\mathrm{MC}$ & 1200 & [26] \\
\hline $\mathrm{Fe}_{52} \mathrm{~V}_{20} \mathrm{Mo}_{10} \mathrm{C}_{18}$ & melt-spinning & $\alpha+\mathrm{MC}$ & 1200 & [26] \\
\hline$\left[\left(\mathrm{Fe}_{1-x} \mathrm{Co}_{x}\right)_{0.75} \mathrm{~B}_{0.2} \mathrm{Si}_{0.05}\right]_{96} \mathrm{Nb}_{4}(x=0.2-0.5)$ & copper mold casting & amorphous & $1220-1250$ & [27] \\
\hline $\mathrm{Fe}_{61} \mathrm{Zr}_{10} \mathrm{Co}_{5} \mathrm{Mo}_{7} \mathrm{~W}_{2} \mathrm{~B}_{15}$ & copper mold casting & amorphous & $1105-1230$ & {$[28]$} \\
\hline $\mathrm{Fe}_{56-61} \mathrm{Co}_{7-8} \mathrm{Ni}_{7-10}(\mathrm{Zr}, \mathrm{Nb}, \mathrm{W})_{10} \mathrm{~B}_{15-20}$ & copper mold casting & amorphous & $1340-1370$ & [29] \\
\hline $\mathrm{Fe}_{61} \mathrm{Y}_{2} \mathrm{Zr}_{8} \mathrm{Co}_{5} \mathrm{Cr}_{2} \mathrm{Mo}_{7} \mathrm{~B}_{15}$ & copper mold casting & amorphous & 1230 & {$[30]$} \\
\hline $\mathrm{Fe}_{41} \mathrm{Co}_{7} \mathrm{Cr}_{15} \mathrm{Mo}_{14} \mathrm{C}_{15} \mathrm{~B}_{6} \mathrm{Y}_{2}$ & copper mold casting & amorphous & 1280 & [33] \\
\hline $\mathrm{Fe}_{52} \mathrm{Co}_{20} \mathrm{~B}_{20} \mathrm{Si}_{4} \mathrm{Nb}_{4}$ & suction casting & amorphous & 1339 & [34] \\
\hline $\mathrm{Fe}_{52} \mathrm{Co}_{20} \mathrm{~B}_{20} \mathrm{Si}_{4} \mathrm{Nb}_{4} \mathrm{Cr}_{1}$ & suction casting & amorphous & 1326 & [34] \\
\hline$\left[\left(\mathrm{Fe}_{0.9-x} \mathrm{Co}_{x} \mathrm{Ni}_{0.1}\right)_{0.75} \mathrm{~B}_{0.2} \mathrm{Si}_{0.05}\right]_{96} \mathrm{Nb}_{4}(x=0.1-0.3)$ & copper mold casting & amorphous & $1210-1240$ & {$[35]$} \\
\hline $\mathrm{Ni}_{60} \mathrm{Nb}_{37} \mathrm{Sn}_{3}$ & injection-casting & amorphous & 1240 & [32] \\
\hline $\mathrm{Ni}_{59.35} \mathrm{Nb}_{34.45} \mathrm{Sn}_{6.2}$ & injection-casting & amorphous & 1280 & [32] \\
\hline $\mathrm{Fe}_{59} \mathrm{Cr}_{16} \mathrm{Mo}_{10} \mathrm{C}_{15}$ & melt-spinning & amorphous & 1020 & [36] \\
\hline $\mathrm{Fe}_{42} \mathrm{Cr}_{32} \mathrm{Mo}_{8} \mathrm{C}_{18}$ & melt-spinning & amorphous & 1120 & [36] \\
\hline $\mathrm{Fe}_{61.5} \mathrm{Cr}_{16} \mathrm{Mo}_{20} \mathrm{C}_{18}$ & melt-spinning & amorphous & 1130 & [36] \\
\hline
\end{tabular}




\section{Figure Captions}

Fig. 1. (a) DSC curves of high-entropy $\left(\mathrm{Fe}_{0.25} \mathrm{Co}_{0.25} \mathrm{Ni}_{0.25} \mathrm{Cr}_{0.125} \mathrm{Mo}_{0.125}\right)_{100-x} \mathrm{~B}_{x}(x=11-$ 14 at $\%$ ) amorphous alloys. (b) The onset temperatures of the first $\left(T_{\mathrm{x} 1}\right)$ and the second $\left(T_{\mathrm{x} 2}\right)$ exothermic peaks as a function of $\mathrm{B}$ content.

Fig. 2. (a) X-ray diffraction patterns of the $11 \mathrm{~B}$ alloy annealed at each exothermic peak temperature for $1.8 \mathrm{ks}$. The DSC data for the 11B amorphous alloy are also shown for comparison. (b) Bright-field TEM image, (c) selected-area electron diffraction pattern and (d) high-resolution TEM image of the 11B alloy annealed for $1.8 \mathrm{ks}$ at $775 \mathrm{~K}$. The red-dashed ellipse marks a region of bcc phase.

Fig. 3. (a) Bright-field TEM image, (b) selected-area electron diffraction pattern, (c) dark-field image taken from (111) fcc reflection spot, (d) high resolution TEM image for the $11 \mathrm{~B}$ alloy annealed for $1.8 \mathrm{ks}$ at $900 \mathrm{~K}$. The yellow and red colors indicate bec and fcc phases, respectively. The dotted lines in (d) present the nanophase interface. The rectangular regions marked with symbols $\mathrm{A}, \mathrm{B}$ and $\mathrm{C}$ in (a) show areas analyzed by EDX spectroscopy. (e,f) HRTEM images showing planar faults and twin boundaries in an fcc nanoparticle in the 11B alloy annealed for $1.8 \mathrm{ks}$ at $900 \mathrm{~K}$.

Fig. 4. (a) X-ray diffraction patterns of the 14B alloy annealed at each exothermic peak temperature for $1.8 \mathrm{ks}$. The DSC data are also shown for comparison. (b) Bright-field TEM image, (c) selected-area election diffraction pattern, (d) dark-field image taken from (111) fcc reflection spot, and (e) high-resolution TEM image for the 14B alloy annealed for $1.8 \mathrm{ks}$ at $783 \mathrm{~K}$. The yellow and red labels indicate bcc and fcc phases, respectively.

Fig. 5. Bright-field TEM micrograph and corresponding EELS maps for elemental components in the 14B alloy annealed for $1.8 \mathrm{ks}$ at $783 \mathrm{~K}$, giving a dispersion of mainly fcc nanocrystals in the residual amorphous phase. There is partitioning of Fe into the crystals and $\mathrm{Cr}$ and $\mathrm{B}$ into the amorphous phase.

Fig. 6. Change in Vickers hardness for the 11B, 12B, 13B and 14B alloys annealed for $1.8 \mathrm{ks}$ at different temperatures. The solid and open symbols indicate plastic and brittle samples, respectively. The precipitation of solid-solution crystalline phases occurs in two stages: for 11-13B these are bcc then fcc, and for 14B the order is reversed. Despite this difference, the hardness is remarkably independent of boron content. 
Fig. 7. (a) Structure, bending plasticity and Vickers hardness for as-spun 11B alloy ribbons prepared at different wheel rotation speeds; (b) the corresponding X-ray diffraction patterns. (c) Bright-field TEM image, (d) selected-area electron diffraction pattern, and (e) high-resolution TEM image for the as-spun 11B alloy ribbon prepared at $30 \mathrm{~m} \mathrm{~s}^{-1}$; EDX spectra and derived compositions for this ribbon are given in Suppl. Fig. 3a,b.

Fig. 8. (a) Photograph of the outer bent surface for as-spun $11 \mathrm{~B}$ and $10 \mathrm{~B}$ alloy ribbons. SEM images showing the deformation structure of the outer bent surface of the as-spun 11B alloy ribbons prepared at rotation speeds of (b) $40 \mathrm{~m} \mathrm{~s}^{-1}$, (c) $20 \mathrm{~m} \mathrm{~s}^{-1}$ and (d) the asspun 10B alloy ribbon prepared at $40 \mathrm{~m} \mathrm{~s}^{-1}$.

Fig. 9. (a) Correlations among between the Bragg angle of the maximum in the amorphous halo, Vickers hardness and B content for the as-spun 11B, 12B, 13B and 14B amorphous alloys. (b) The change in Vickers hardness with $B$ content for $\left(\mathrm{Fe}_{0.25} \mathrm{Co}_{0.25} \mathrm{Ni}_{0.25} \mathrm{Cr}_{0.125} \mathrm{Mo}_{0.125}\right)_{100-x} \mathrm{~B}_{x}(x=11-31$ at $\%)$ amorphous alloys. (c) Relation between Vickers hardness and total volume fraction of $[\mathrm{bcc}+\mathrm{fcc}]$ phases for the partially crystallized 11B alloy.

Fig. 10. Schematic illustration of a temperature-time-transformation (TTT) diagram for the 11B alloy subjected to continuous cooling from liquid and continuous heating from amorphous phase.

Suppl. Fig. 1. EDX spectra and derived compositions of (a) bcc phase, (b) fcc phase and (c) amorphous phase in the $\left[\mathrm{am}^{\prime \prime}+\mathrm{bcc}+\mathrm{fcc}\right]$ mixture obtained by annealing for 1.8 ks at $900 \mathrm{~K}$ for $11 \mathrm{~B}$ alloy.

Suppl. Fig. 2. (a) M-H hysteresis curve for the 11B alloy annealed for $1.8 \mathrm{ks}$ at different temperatures. (b) Hysteresis magnetization-magnetic field (B-H) loops of the 11B alloy in as-spun and annealed states. (c) the change in saturation magnetization at room temperature with annealing temperature for the 11B alloy. The DSC curve is also shown for comparison.

Suppl. Fig. 3. EDX spectra and derived compositions of (a) fcc phase and (b) amorphous phase in the $\left[\mathrm{am}^{\prime}+\mathrm{fcc}\right]$ mixture in as-spun 11B alloy ribbon prepared at 30 
$\mathrm{m} \mathrm{s}^{-1}$.

\section{FIGURES}
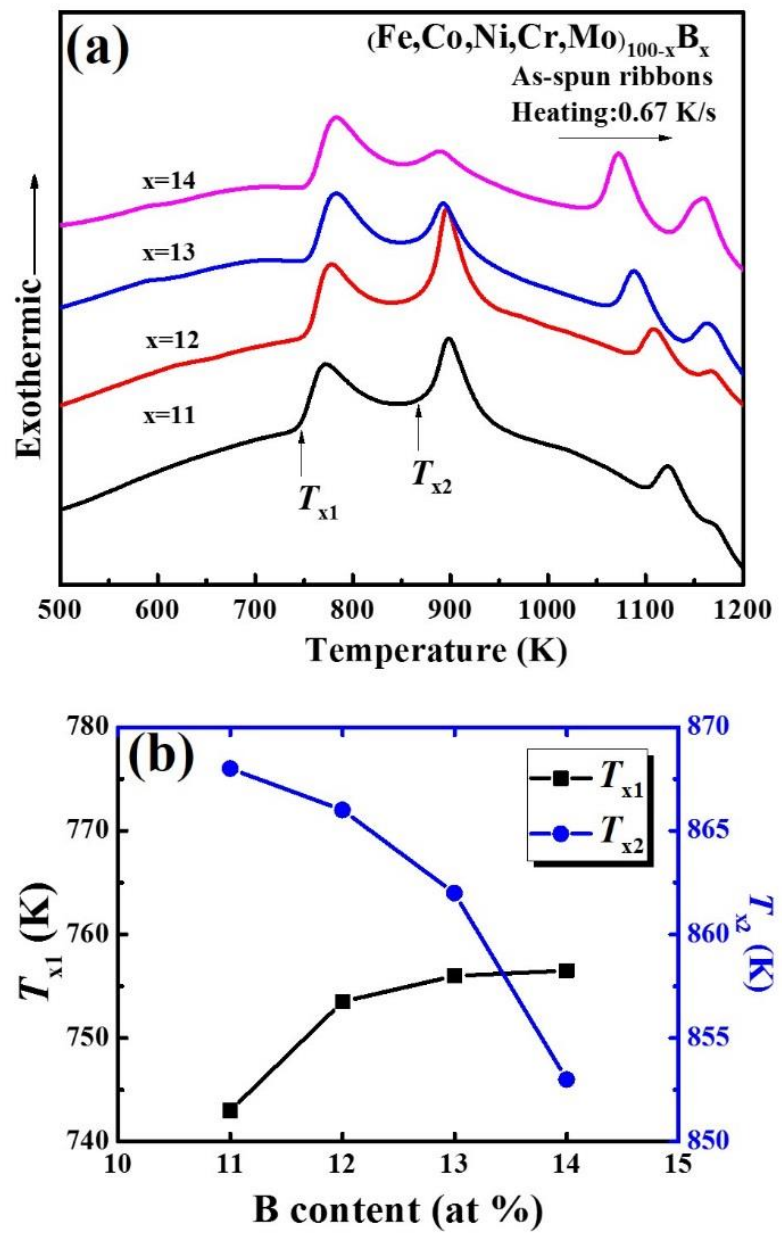

Fig. 1. (a) DSC curves of high-entropy $\left(\mathrm{Fe}_{0.25} \mathrm{Co}_{0.25} \mathrm{Ni}_{0.25} \mathrm{Cr}_{0.125} \mathrm{Mo}_{0.125}\right)_{100-x} \mathrm{~B}_{x}(x=11-$ 14 at $\%$ ) amorphous alloys. (b) The onset temperatures of the first $\left(T_{\mathrm{x} 1}\right)$ and the second $\left(T_{\mathrm{x} 2}\right)$ exothermic peaks as a function of $\mathrm{B}$ content. 

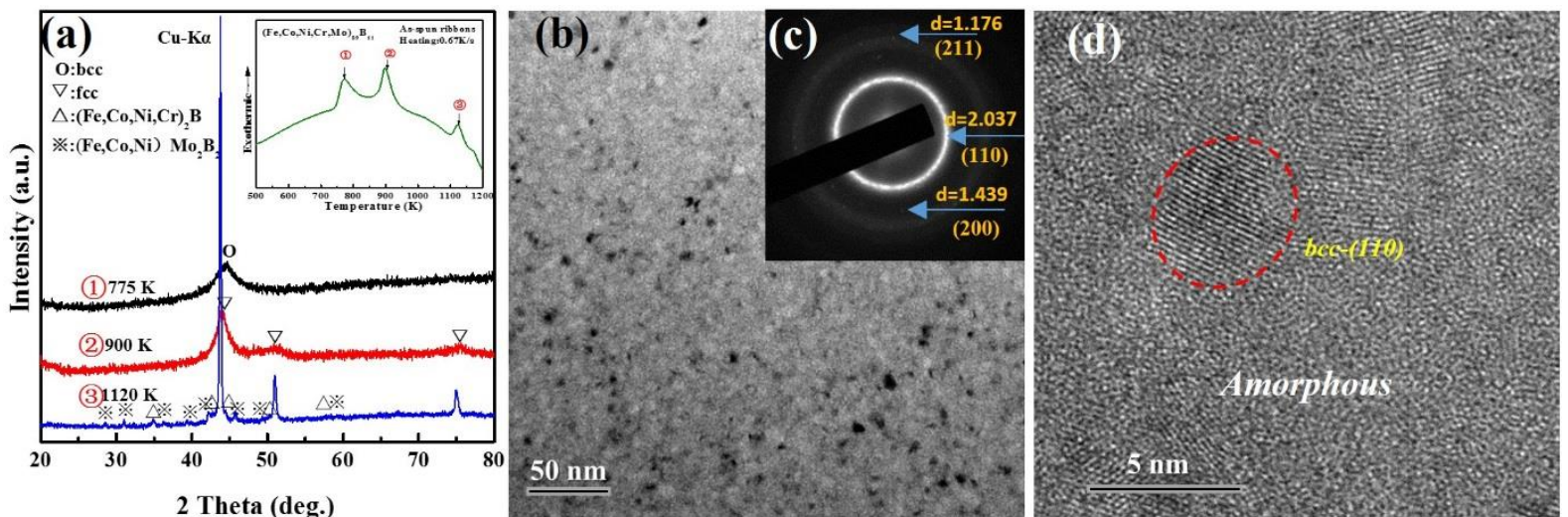

Fig. 2. (a) X-ray diffraction patterns of the $11 \mathrm{~B}$ alloy annealed at each exothermic peak temperature for $1.8 \mathrm{ks}$. The DSC data for the 11B amorphous alloy are also shown for comparison. (b) Bright-field TEM image, (c) selected-area electron diffraction pattern and (d) high-resolution TEM image of the 11B alloy annealed for $1.8 \mathrm{ks}$ at $775 \mathrm{~K}$. The red-dashed ellipse marks a region of bcc phase. 

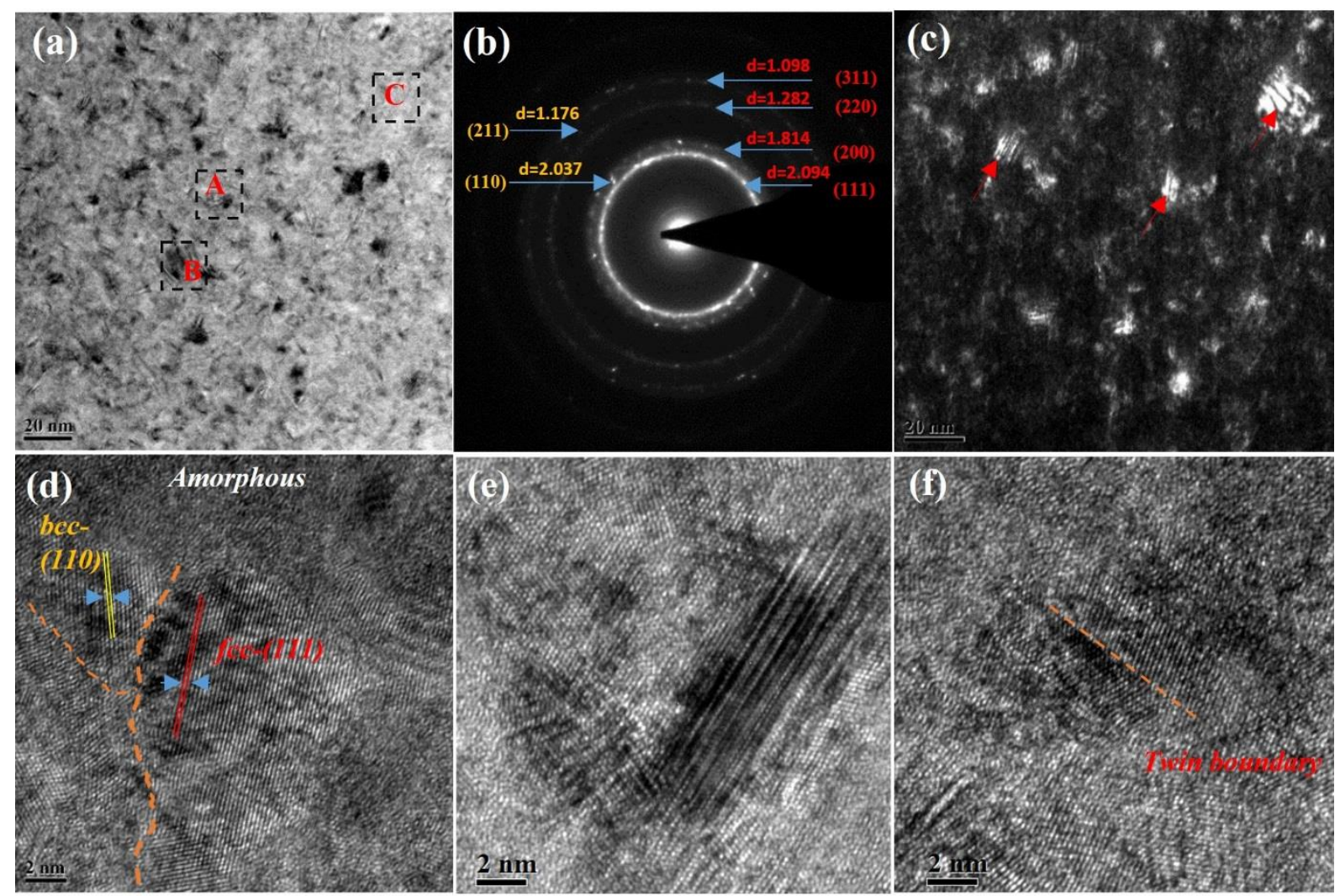

Fig. 3. (a) Bright-field TEM image, (b) selected-area electron diffraction pattern, (c) dark-field image taken from (111) fcc reflection spot, (d) high-resolution TEM image for the $11 \mathrm{~B}$ alloy annealed for $1.8 \mathrm{ks}$ at $900 \mathrm{~K}$. The yellow and red colors indicate bcc and fcc phases, respectively. The dotted lines in (d) present the nanophase interface. The rectangular regions marked with symbols $\mathrm{A}, \mathrm{B}$ and $\mathrm{C}$ in (a) show areas analyzed by EDX spectroscopy. (e,f) HRTEM images showing planar faults and twin boundaries in an fcc nanoparticle in the $11 \mathrm{~B}$ alloy annealed for $1.8 \mathrm{ks}$ at $900 \mathrm{~K}$.

It will be good, somehow to improve the visibility of the labels in the figures. The scale markers could be bigger, and perhaps some of the other labels also. 

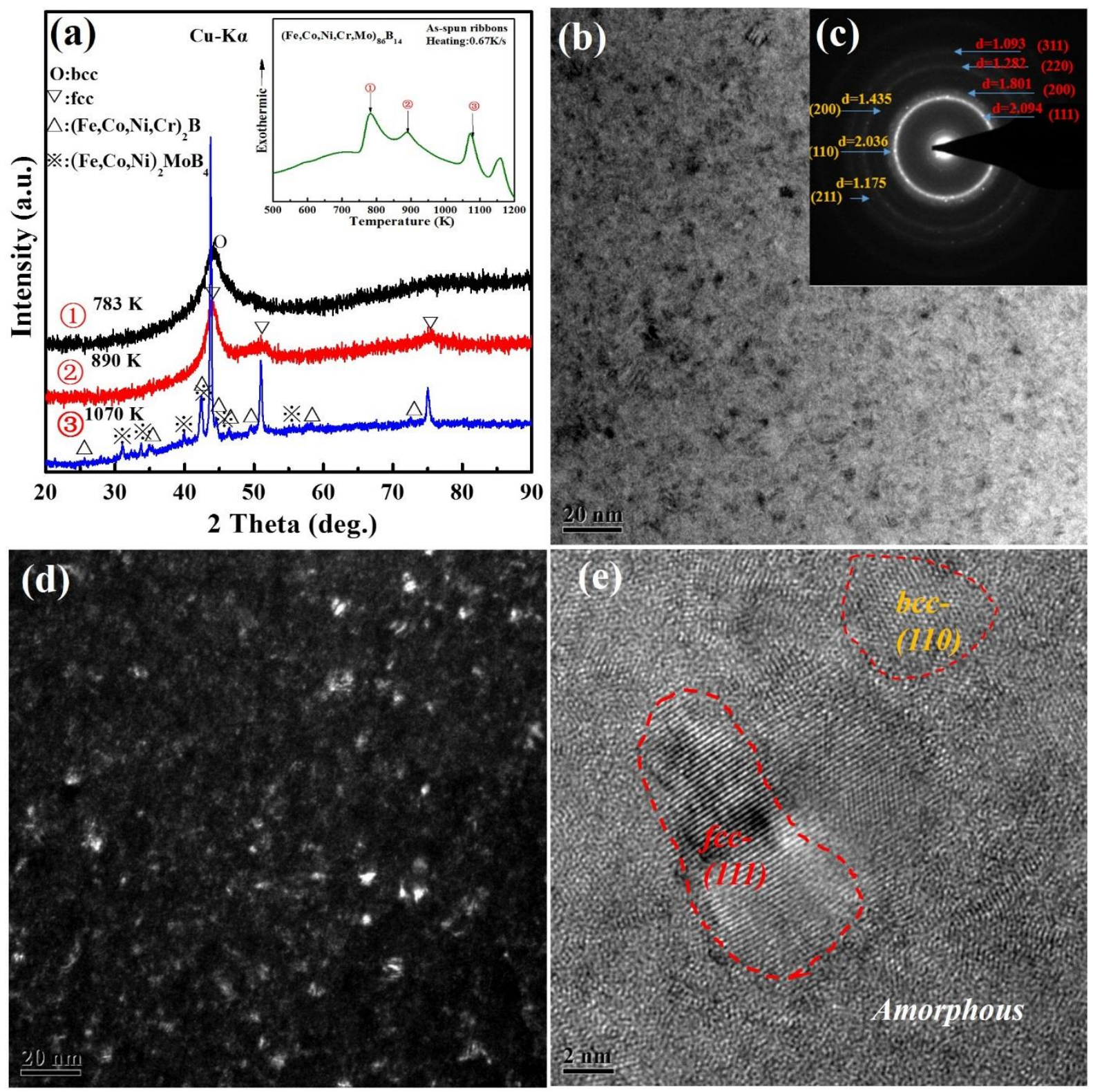

Fig. 4. (a) X-ray diffraction patterns of the 14B alloy annealed at each exothermic peak temperature for $1.8 \mathrm{ks}$. The DSC data are also shown for comparison. (b) Bright-field TEM image, (c) selected-area election diffraction pattern, (d) dark-field image taken from (111) fcc reflection spot, and (e) high-resolution TEM image for the 14B alloy annealed for $1.8 \mathrm{ks}$ at $783 \mathrm{~K}$. The yellow and red labels indicate bcc and fcc phases, respectively. Again some attention is needed to the visibility of the scale-markers and colored labels. 


\section{$0.02 \mu \mathrm{m}$}
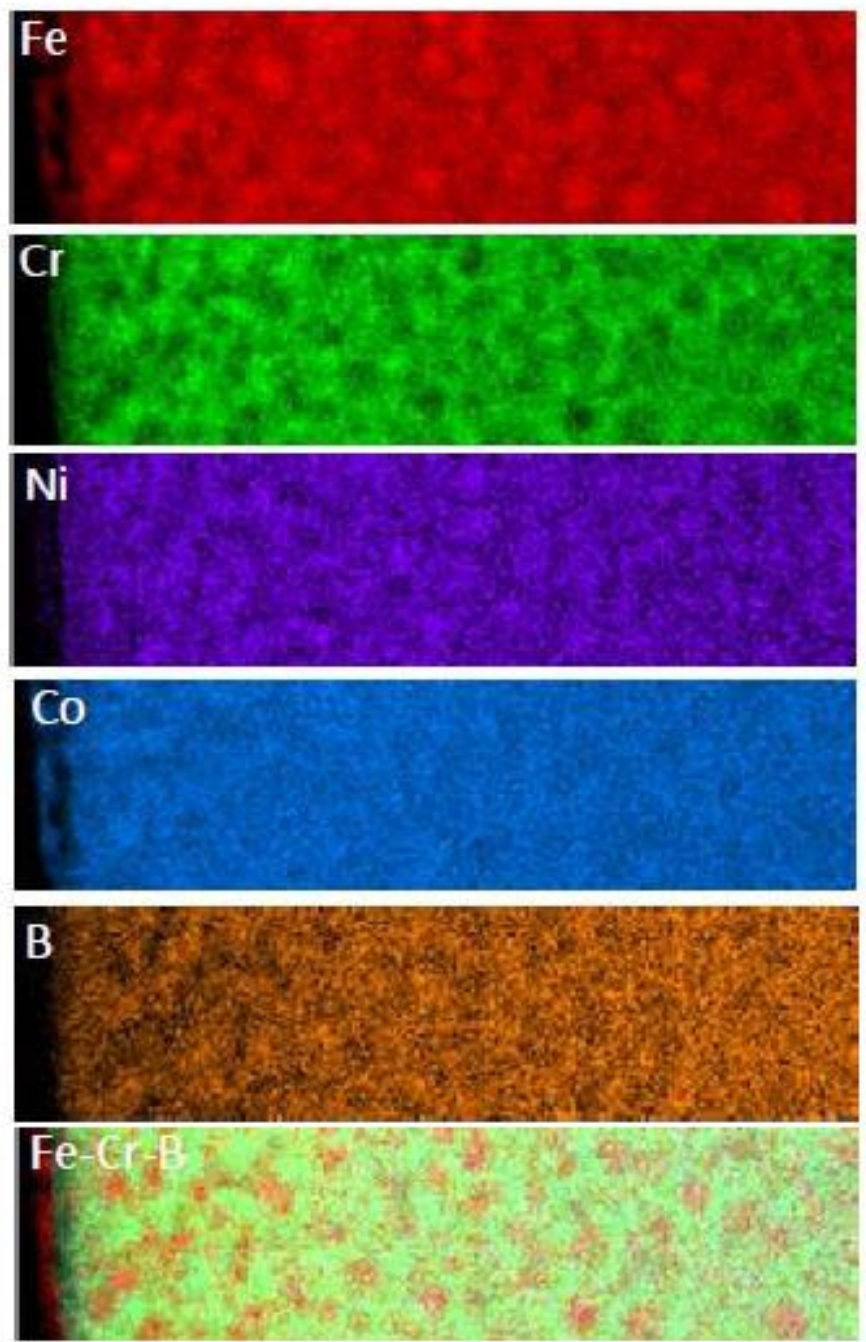

Fig. 5. Bright-field TEM micrograph and corresponding EELS maps for elemental components in the $14 \mathrm{~B}$ alloy annealed for $1.8 \mathrm{ks}$ at $783 \mathrm{~K}$, giving a dispersion of mainly fcc nanocrystals in the residual amorphous phase. There is partitioning of Fe into the crystals and $\mathrm{Cr}$ and $\mathrm{B}$ into the amorphous phase. 


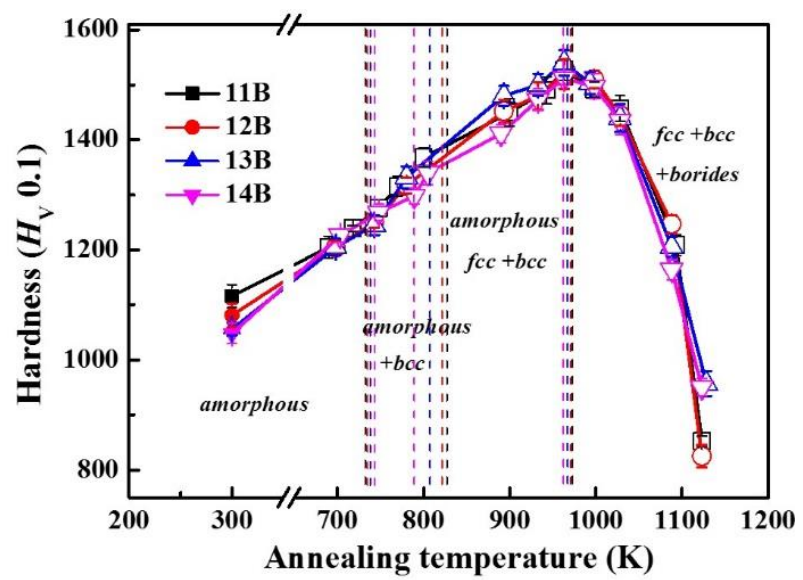

Fig. 6. Change in Vickers hardness for the 11B, 12B, 13B and 14B alloys annealed for $1.8 \mathrm{ks}$ at different temperatures. The solid and open symbols indicate plastic and brittle samples, respectively. The precipitation of solid-solution crystalline phases occurs in two stages: for 11-13B these are bcc then fcc, and for 14B the order is reversed. Despite this difference, the hardness is remarkably independent of boron content.

Suggest to re-label the central region as below:

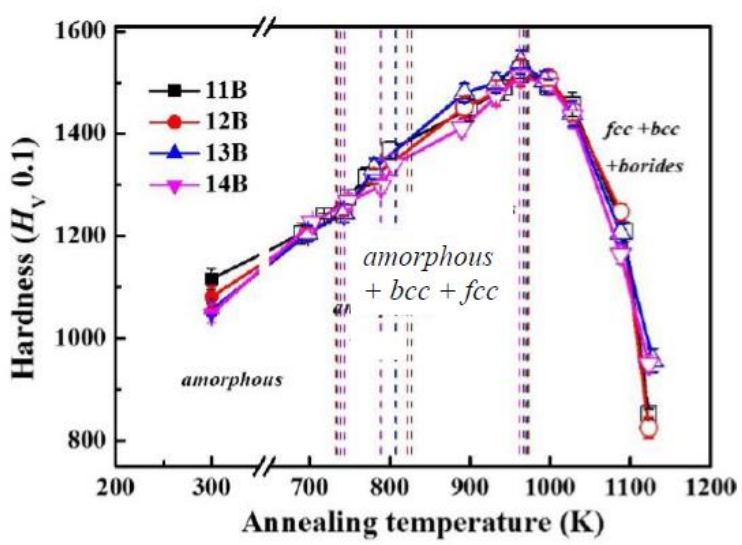



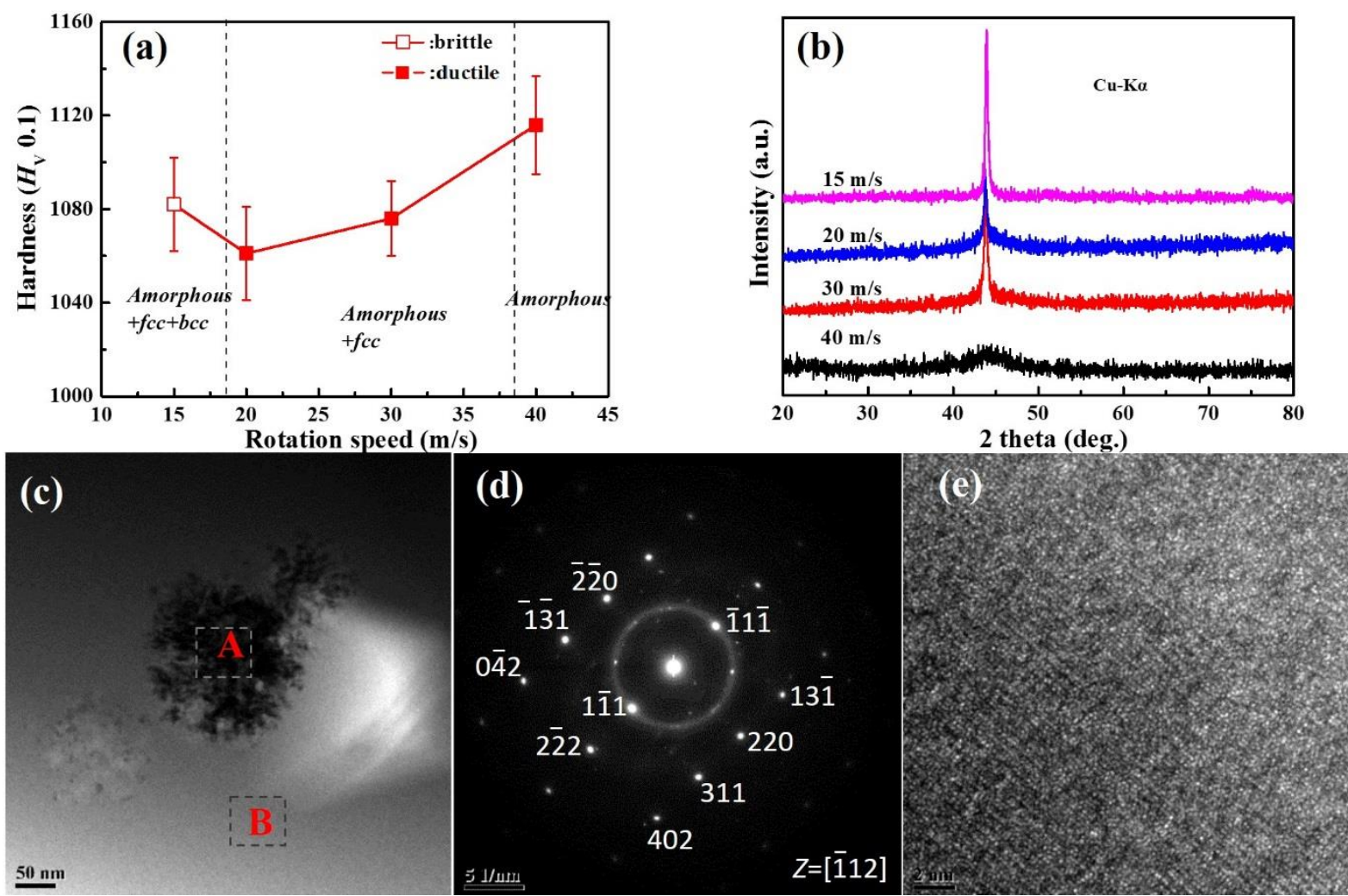

Fig. 7. (a) Structure, bending ductility and Vickers hardness for as-spun 11B alloy ribbons prepared at different wheel rotation speeds; (b) the corresponding X-ray diffraction patterns. (c) Bright-field TEM image, (d) selected-area electron diffraction pattern, and (e) high-resolution TEM image for the as-spun 11B alloy ribbon prepared at $30 \mathrm{~m} \mathrm{~s}^{-1}$; EDX spectra and derived compositions for this ribbon are given in Suppl. Fig. 3a,b. 

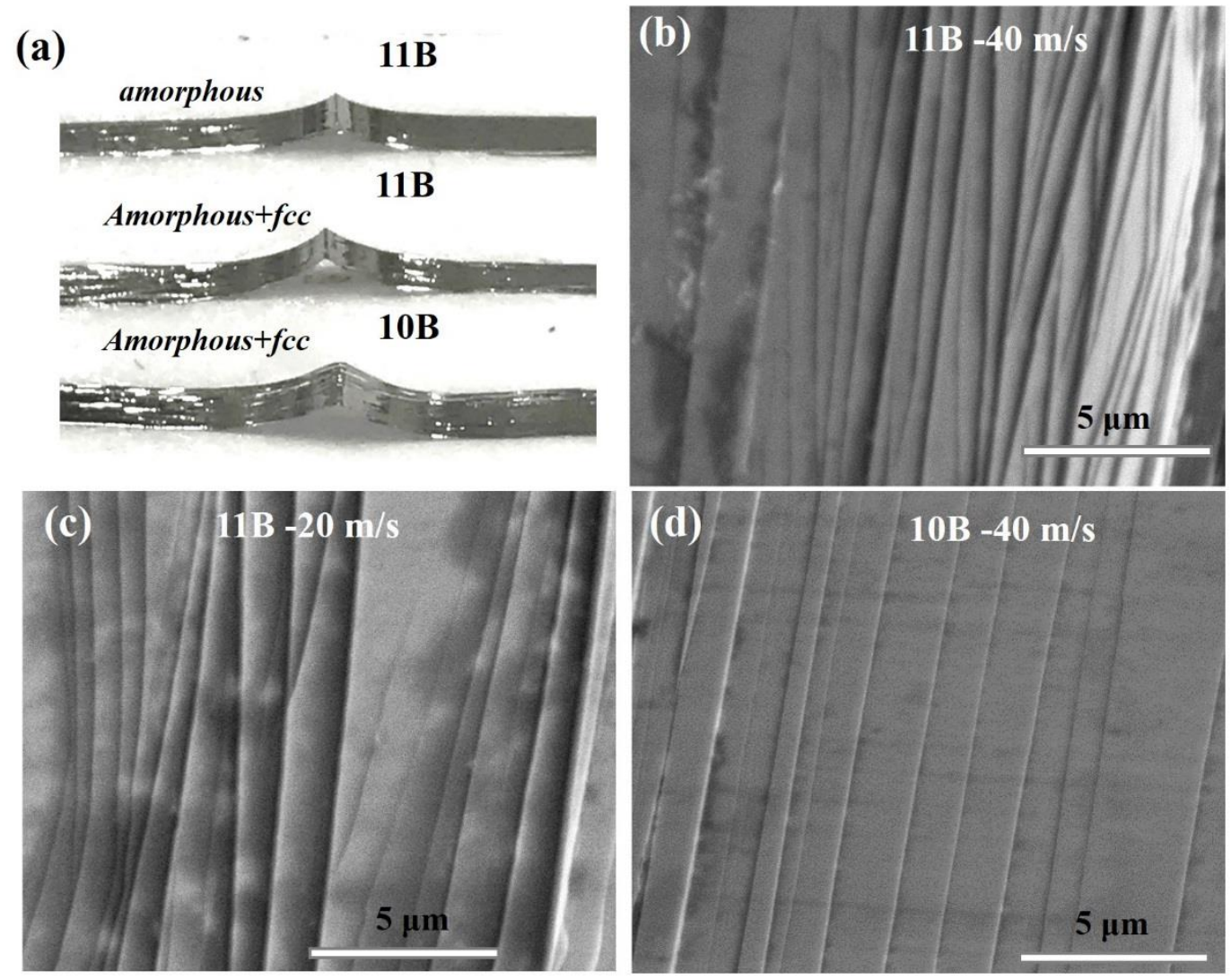

Fig. 8. (a) Photograph of the outer bent surface for as-spun $11 \mathrm{~B}$ and $10 \mathrm{~B}$ alloy ribbons. SEM images showing the deformation structure of the outer bent surface of the as-spun 11B alloy ribbons prepared at rotation speeds of (b) $40 \mathrm{~m} \mathrm{~s}^{-1}$, (c) $20 \mathrm{~m} \mathrm{~s}^{-1}$ and (d) the asspun 10B alloy ribbon prepared at $40 \mathrm{~m} \mathrm{~s}^{-1}$. 

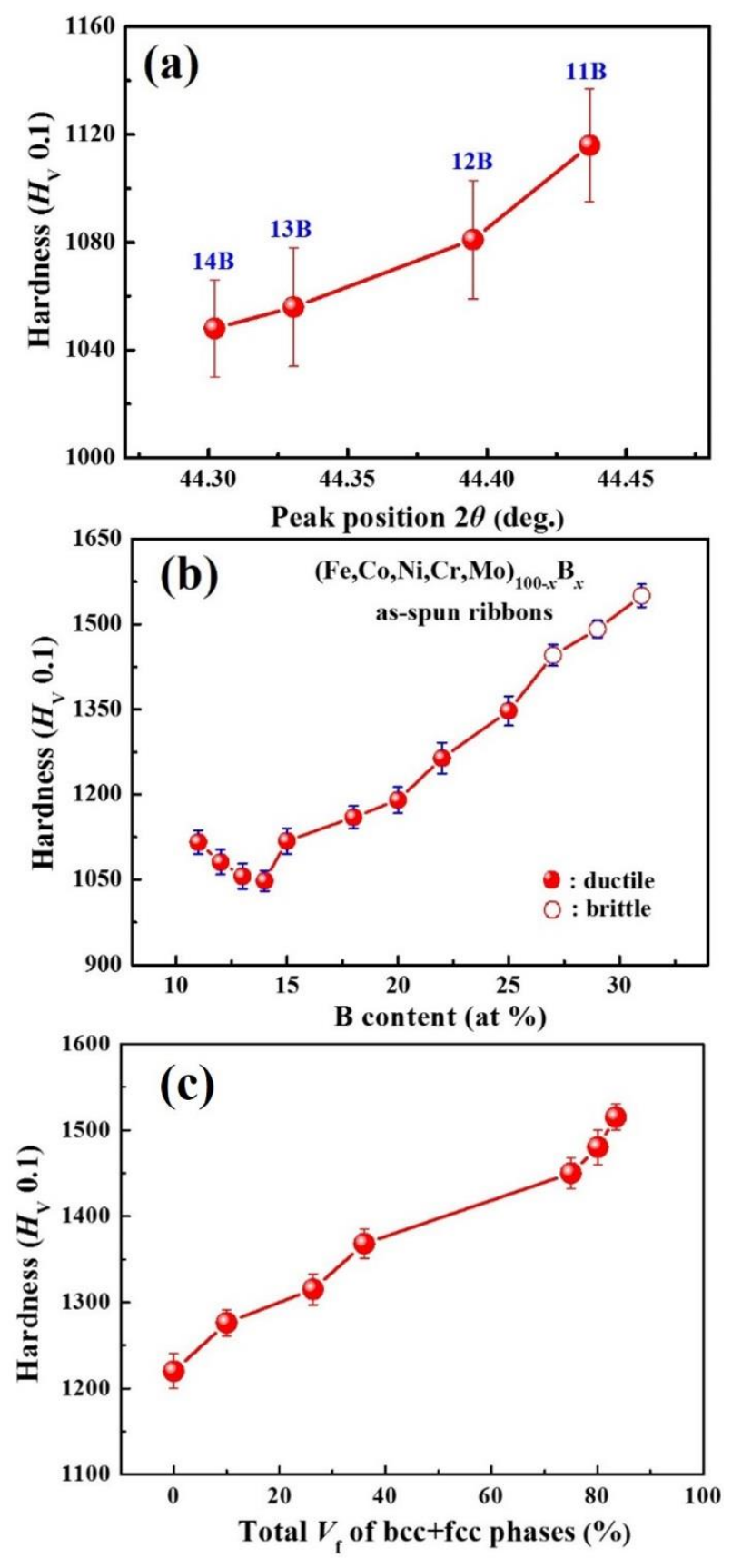

Fig. 9. (a) Correlations among between the Bragg angle of the maximum in the amorphous halo, Vickers hardness and B content for the as-spun 11B, 12B, 13B and 14B amorphous alloys. (b) The change in Vickers hardness with $\mathrm{B}$ content for $\left(\mathrm{Fe}_{0.25} \mathrm{Co}_{0.25} \mathrm{Ni}_{0.25} \mathrm{Cr}_{0.125} \mathrm{Mo}_{0.125}\right)_{100-x} \mathrm{~B}_{x}(x=11-31$ at\%) amorphous alloys. (c) Relation between Vickers hardness and total volume fraction of [bcc $+\mathrm{fcc}]$ phases for the partially crystallized 11B alloy. 


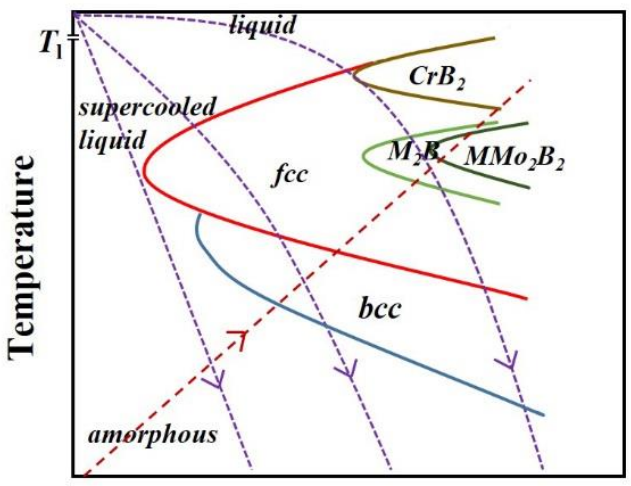

Time

Fig. 10. Schematic illustration of a temperature-time-transformation (TTT) diagram for the $11 \mathrm{~B}$ alloy subjected to continuous cooling from liquid and continuous heating from amorphous phase. 


\section{SUPPLEMENTARY MATERIAL}

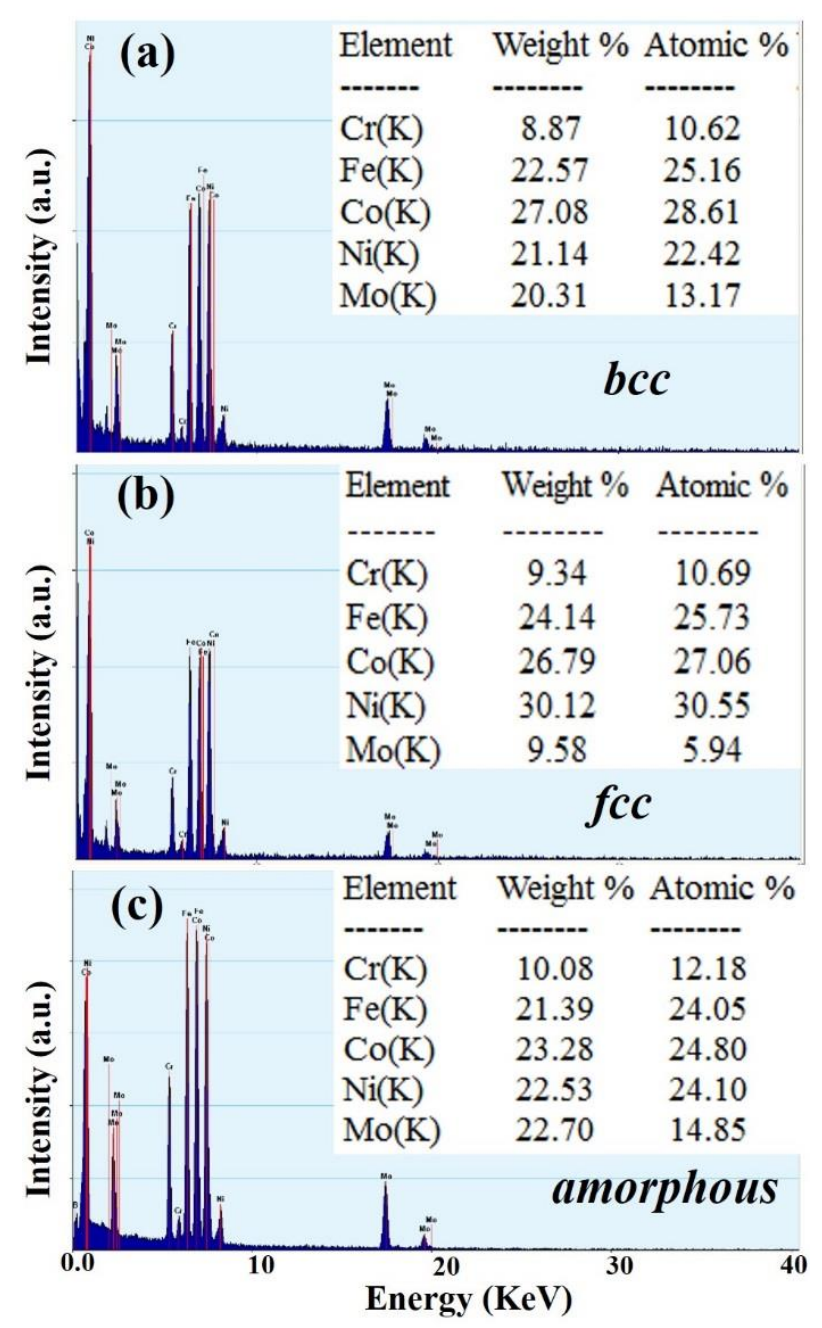

Suppl. Fig. 1. EDX spectra and derived compositions of (a) bcc phase, (b) fcc phase and (c) amorphous phase in the $\left[a m^{\prime \prime}+\right.$ bcc + fcc] mixture obtained by annealing for 1.8 ks at $900 \mathrm{~K}$ for $11 \mathrm{~B}$ alloy.

The label on the horizontal axis should be Energy (keV), not Energy $(\mathrm{KeV})$ 

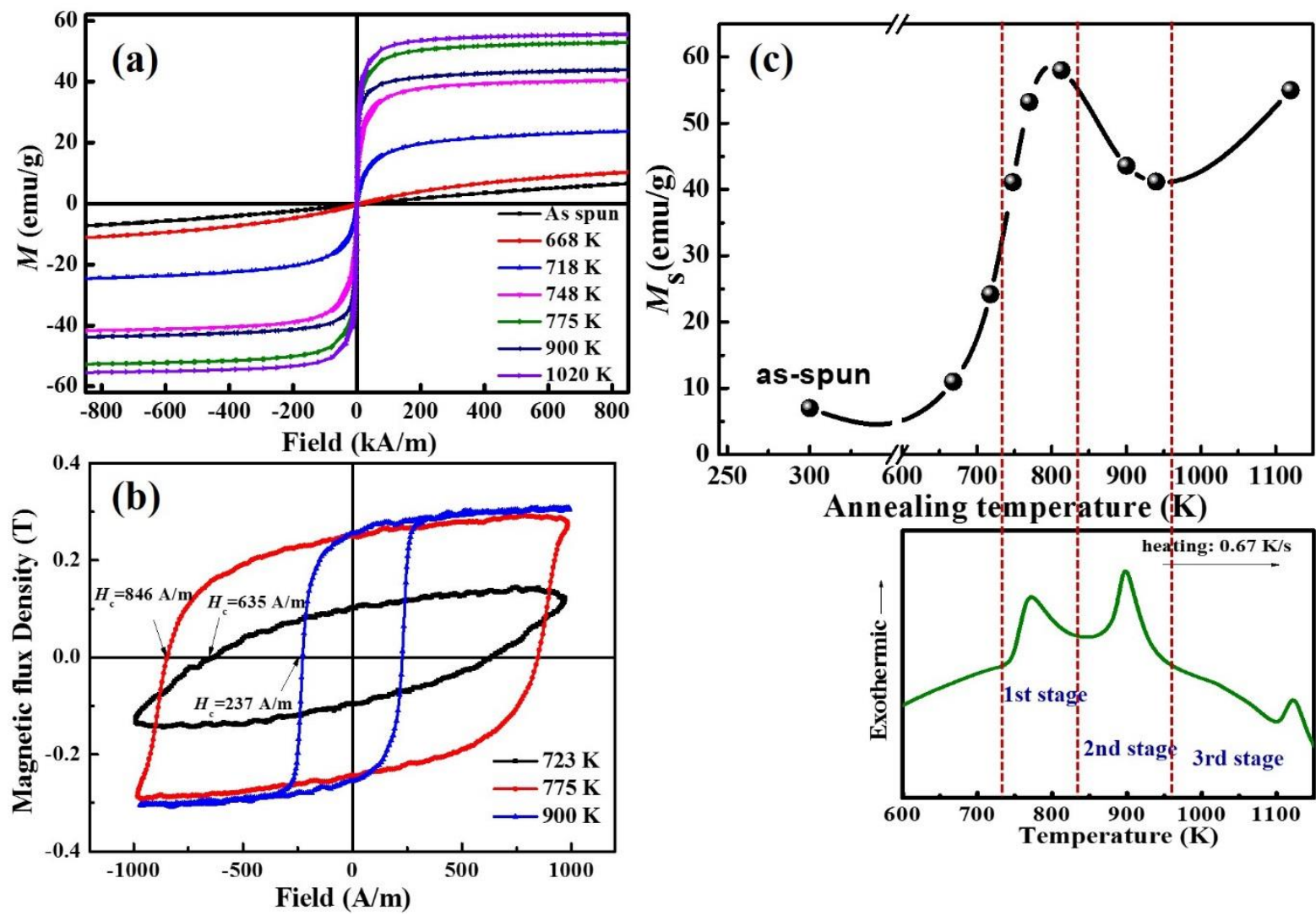

Suppl. Fig. 2. (a) M-H hysteresis curve for the $11 \mathrm{~B}$ alloy annealed for $1.8 \mathrm{ks}$ at different temperatures. (b) Hysteresis magnetization-magnetic field (B-H) loops of the 11B alloy in as-spun and annealed states. (c) the change in saturation magnetization at room temperature with annealing temperature for the 11B alloy. The DSC curve is also shown for comparison. 

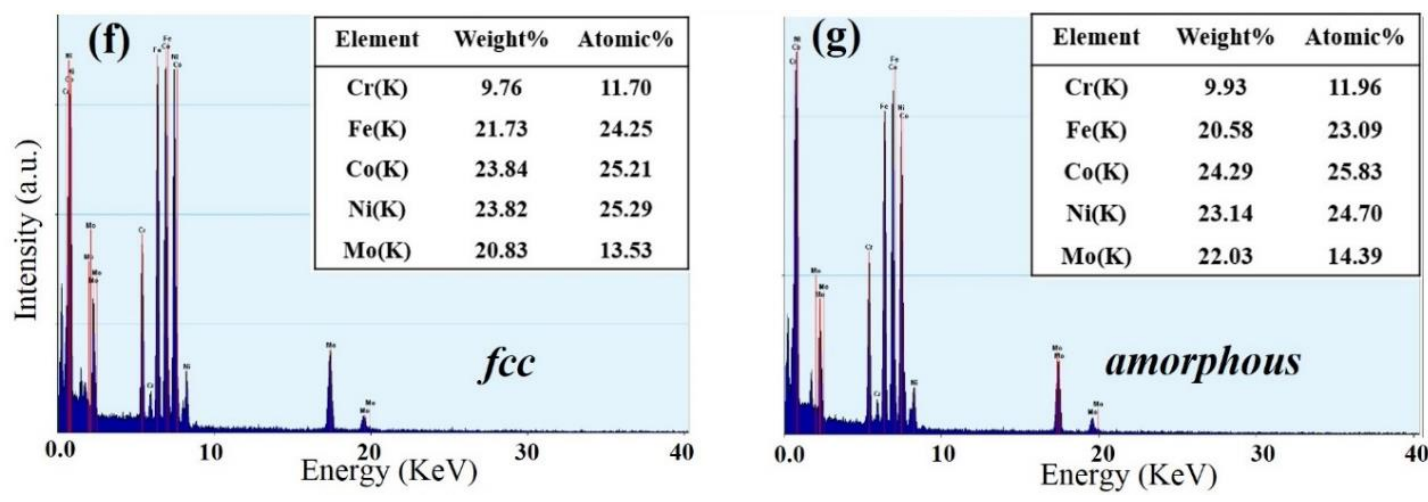

Suppl. Fig. 3. EDX spectra and derived compositions of (a) fcc phase and (b) amorphous phase in the $\left[\mathrm{am}^{\prime}+\mathrm{fcc}\right]$ mixture in as-spun $11 \mathrm{~B}$ alloy ribbon prepared at $30 \mathrm{~m}$ $\mathrm{s}^{-1}$.

Changes labels in the figure to (a) and (b). 